\title{
The timing of sea-level high-stands during Marine Isotope Stages 7.5 and 9: Constraints from the uranium-series dating of fossil corals from Henderson Island
}

\author{
Morten B. Andersen ${ }^{\mathrm{a}, \mathrm{b}, *}$, Claudine H. Stirling ${ }^{\mathrm{a}, \mathrm{c}}$, Emma-Kate Potter ${ }^{\mathrm{a}}$, \\ Alex N. Halliday ${ }^{\mathrm{a}, \mathrm{d}}$, Steve G. Blake ${ }^{\mathrm{e}}$, Malcolm T. McCulloch ${ }^{\mathrm{f}}$, Bridget F. Ayling ${ }^{\mathrm{f}}$, \\ Michael J. O'Leary ${ }^{\mathrm{g}}$ \\ ${ }^{a}$ ETH Zurich, Institute for Isotope Geochemistry and Mineral Resources, ETH Zentrum, Zurich 8092, Switzerland \\ ${ }^{\mathrm{b}}$ Bristol Isotope Group, Department of Earth Sciences, University of Bristol, Parks Road, Bristol, United Kingdom \\ ${ }^{\mathrm{c}}$ Department of Chemistry, University of Otago, P.O. Box 56, Union Place, Dunedin, New Zealand \\ ${ }^{\mathrm{d}}$ Department of Earth Sciences, Parks Road, Oxford OX1 3PR, United Kingdom \\ ${ }^{\mathrm{e}}$ Western Australian Marine Science Institution (WAMSI), The University of Western Australia, 35 Stirling Highway, Crawley, WA 6009, \\ Australia \\ ${ }^{\mathrm{f}}$ Research School of Earth Sciences, The Australian National University, Canberra ACT 0200, Australia \\ ${ }^{g}$ Department of Environmental and Geographic Sciences, Manchester Metropolitan University, Manchester M1 5GD, United Kingdom
}

Received 16 July 2009; accepted in revised form 16 March 2010; available online 4 April 2010

\begin{abstract}
Direct dating of fossil coral reefs using the U-series chronometer provides an important independent test of the Milankovitch orbital forcing theory of climate change. However, well-dated fossil corals pre-dating the last interglacial period ( $>130$ thousand years ago; ka) are scarce due to, (1) a lack of sampling localities, (2) insufficient analytical precision in U-series dating methods, and (3) diagenesis which acts to violate the assumption of closed-system U-series isotopic decay in fossil corals. Here we present 50 new high-precision U-series age determinations for fossil corals from Henderson Island, an emergent coral atoll in the central South Pacific. U-series age determinations associated with the Marine Isotope Stage (MIS) 9 interglacial and MIS 7.5 interstadial periods are reported. The fossil corals show relatively little open-system U-series behaviour in comparison to other localities with fossil coral reefs formed prior to the last glacial cycle, however, open-system U-series behaviour is still evident in most of the dated corals. In particular, percent-level shifts in the $\left[{ }^{230} \mathrm{Th} /{ }^{238} \mathrm{U}\right]$ act $\operatorname{composition}$ are observed, leading to conventional U-series ages that are significantly younger or older than the true sample age. This open-system U-series behaviour is not accounted for by any of the open-system U-series models, indicating that new models should be derived. The new U-series ages reported here support and extend earlier findings reported in Stirling et al. (2001), providing evidence of prolific coral reef development on Henderson Island at 320 ka, most likely correlated with MIS 9.3, and subsequent reef development at $\sim 307 \mathrm{ka}$ during MIS 9.1, while relative sea-level was potentially $\sim 20 \mathrm{~m}$ lower than during MIS 9.3. The U-series ages for additional well-preserved fossil corals are suggestive of minor reef development on Henderson Island during MIS $7.5(245-230 \mathrm{ka})$ at $240.3 \pm 0.8$ and $234.7 \pm 1.3 \mathrm{ka}$. All U-series observations are consistent with the Milankovitch theory of climate change, in terms of the timing of onset and termination of the dated interglacial and interstadial periods. The best preserved samples also suggest that the oceanic ${ }^{234} \mathrm{U} /{ }^{238} \mathrm{U}$ during MIS 9 and MIS 7.5 was within five permil of the modern open ocean composition.
\end{abstract}

(C) 2010 Elsevier Ltd. All rights reserved.

\footnotetext{
* Corresponding author at: Bristol Isotope Group, Department of Earth Sciences, University of Bristol, Parks Road, Bristol, United Kingdom. Tel.: +41 1632 6983; fax: +41632 21179.

E-mail address: morten.andersen@bris.ac.uk (M.B. Andersen).
} 


\section{INTRODUCTION}

The waxing and waning of the continental ice-sheets during the Quaternary time period, and the resulting fluctuations in eustatic sea-level as water is exchanged between marine and terrestrial reservoirs, are crucial components of the Earth's climate system (e.g. Lambeck et al., 2002). Continuous records of past ice volumes and sea-level are recorded in marine sediments (e.g. Bintanja et al., 2005) and have been assigned a chronology based on orbital forcing theory, assuming summer solar insolation predictions at high northern latitudes drive glacial-interglacial climate variability (Milankovitch, 1941). Coastal markers are also significant in the reconstruction of past sea-level fluctuations, providing estimates of sea-level relative to the continental crust (e.g. Broecker, 1966). For instance, speleothems growing in coastal caves cease forming when the caves become flooded, thereby providing a maximum constraint on relative sea-level during episodes of rising sea-level (e.g. Richards and Dorale, 2003). Also, fossil corals growing at or near the sea surface provide a minimum estimate of relative sea-level at the time the paleo-reefs formed (e.g. Edwards et al., 2003). Importantly, the carbonate forming the structure of corals and speleothems can be directly dated using the uranium decay series $\left({ }^{230} \mathrm{Th}-{ }^{234} \mathrm{U}-{ }^{238} \mathrm{U}\right.$ and $\left.{ }^{231} \mathrm{~Pa}-{ }^{235} \mathrm{U}\right)$ chronometers, providing absolute chronologies of sea-level events that are independent of Milankovitch orbital forcing theory and a means to independently test models of sea-level and climate change (e.g. Bard et al., 1991; Dorale et al., 2010; Dutton et al., 2009; Esat et al., 1999; Gallup et al., 1994, 2002; Stirling et al., 1998; Thomas et al., 2009). Specifically, the timing of the sea-level highstands constrained by the U-series observations should coincide with or slightly post-date the predicted insolation maxima in order to validate the Milankovitch theory of climate change; U-series observations pre-dating the insolation predictions would imply other forcing mechanism/s.

Most reliably dated fossil corals are those sampled from reefs that formed during the last glacial cycle, and these observations have dramatically improved our understanding of the timing, duration and character of sea-level fluctuations within this period (e.g. Bard et al., 1996a; Cutler et al., 2003; Yokoyama et al., 2001). However, despite extended studies of the last interglacial period, defined in marine oxygen isotope terminology as Marine Isotope Stage (MIS) 5.5, the timing of the preceding MIS 6 deglaciation remains controversial, as some studies argue for an earlier onset of sea-level rise compared with predictions based on the Milankovitch theory (e.g. Esat et al., 1999; Gallup et al., 2002; Henderson and Slowey, 2000; Thomas et al., 2009). These studies invoke other forcing mechanisms and Earth system feedback responses to explain the earlier timing of deglaciation. To gain an improved understanding of these processes and examine whether they are typical phenomena in the climate record, it is important to investigate paleo-sea-level markers that formed during earlier glacialinterglacial cycles. However, the study of older fossil corals has generally been severely limited by two issues: (1) age-related differences in the U-series isotopic composition decrease with time as the isotope ratios approach radioactive secular equilibrium and become increasingly difficult to measure, and (2) fossil corals are increasingly prone to diagenesis with increasing sample age.

The former has, until recently, limited the acquisition of precise and reliable U-series measurements for fossil reef systems formed prior to the last interglacial period because high-precision U-series measurements are essential for older samples. U-series chronology is based on the extent of radioactive disequilibrium between the parent ${ }^{238} \mathrm{U}$ nuclide and its intermediate daughters, ${ }^{234} \mathrm{U}$ and ${ }^{230} \mathrm{Th}$, expressed via the ratios ${ }^{234} \mathrm{U} /{ }^{238} \mathrm{U}$ and ${ }^{230} \mathrm{Th} /{ }^{238} \mathrm{U}$. It is common practice to reformulate ${ }^{234} \mathrm{U} /{ }^{238} \mathrm{U}$ into $\delta$-notation, whereby the present day value is denoted by $\delta^{234} \mathrm{U}$ and the initial backcalculated value (calculated from the coral's present day $\delta^{234} U$ and its U-series age) is referred to as $\delta^{234} U_{i}$. Uranium-series dating methods have developed considerably with the advent of multiple-collector mass spectrometry using thermal ionization and inductively coupled plasma sources (TIMS and MC-ICPMS, respectively). Measurement of the U-Th isotopes down to the permil level is now routinely achievable (e.g. Cheng et al., 2000; Deschamps et al., 2003; Fietzke et al., 2005; Gallup et al., 2002; Goldstein and Stirling, 2003; Robinson et al., 2002; Stirling et al., 1998). Further developments have continued to improve these techniques to achieve the sub-permil levels of precision that are essential to resolve climatic events separated by less than a few thousand years for samples older than 200 ka (Andersen et al., 2008; Stirling et al., 2001).

For several decades, it has been widely recognized that open-system behaviour of the U-series isotopes in aragonitic carbonates greatly limits the accuracy of the U-series chronometer, particularly in older samples, where the time-integrated effects of diagenesis are most evident (e.g. Bender et al., 1979; Chen et al., 1991; Edwards et al., 1997; Fruijtier et al., 2000; Gallup et al., 1994; Hamelin et al., 1991; Henderson et al., 1993). Several a priori screening criteria have been proposed to reject altered corals. Specifically, only samples displaying primary aragonitic textures and no evidence of secondary calcite recrystallisation are selected for U-series dating purposes. However, these criteria have only proven useful for screening out very altered samples. Thus a posteriori criteria based on the $\mathrm{U}$-series systematics themselves are mandatory for assessing $\mathrm{U}$-series age reliability, including sensible $\mathrm{U}$ concentrations and minimal contamination from detrital ${ }^{232} \mathrm{Th}$. Another test of U-series open-system behaviour is to compare ages derived from both the ${ }^{230} \mathrm{Th}-{ }^{234} \mathrm{U}-{ }^{238} \mathrm{U}$ and the ${ }^{235} \mathrm{U}^{231} \mathrm{~Pa}$ chronometers on the same sample (Chiu et al., 2006; Cutler et al., 2003; Edwards et al., 1997). Although comparison and consistency of the $\mathrm{Th} / \mathrm{U}$ and $\mathrm{Pa} / \mathrm{U}$ chronometers can be regarded as a very robust test for age reliability, as is the case with the other approaches, it is not always conclusive.

Furthermore, one of the most widely utilized post-analysis tests of U-series age reliability is to compare the sample's initial $\delta^{234} U_{i}$ with the modern $\delta^{234} U$ seawater composition of $147 \%$ (Gallup et al., 1994; Stirling and Andersen, 2009), on the basis that corals incorporate the seawater $\delta^{234} \mathrm{U}$ signature during growth. It is commonly assumed that the seawater $\delta^{234} \mathrm{U}$ has not deviated signifi- 
cantly away from the present day value at any time during the last $400 \mathrm{ka}$ (Henderson, 2002). Thus the consensus has been to reject fossil corals having an initial $\delta^{234} U_{i}$ that is significantly different from the modern seawater value assuming 'anomalous' values are a consequence of U-series open-system behaviour. Importantly, several recent studies have suggested the possibility of permil to percent-level $\delta^{234} \mathrm{U}$ variations in the open oceans on glacial-interglacial scales (Cutler et al., 2004; Esat and Yokoyama, 2006; Hughen et al., 2004; Robinson et al., 2004) and the implication is that the seawater ${ }^{234} \mathrm{U} /{ }^{238} \mathrm{U}$ is under-constrained in the past (Stirling and Andersen, 2009). This implies that the application of a fixed $\delta^{234} U$ screening criteria should be used with caution.

U-series open-system behaviour in fossil corals often shows broadly systematic behaviour towards elevated ${ }^{230} \mathrm{Th} /{ }^{238} \mathrm{U}$ and ${ }^{234} \mathrm{U} /{ }^{238} \mathrm{U}$, suggestive of a diagenetic mechanism that systematically adds both ${ }^{230} \mathrm{Th}$ and ${ }^{234} \mathrm{U}$ to the coral skeleton (e.g. Gallup et al., 1994). Although the exact mechanism for this ${ }^{230} \mathrm{Th}-{ }^{234} \mathrm{U}$ addition is not well understood, several open-system U-series models have been developed to mathematically or empirically describe these systematic trends. These models offer the potential to convert inaccurate conventionally-dated U-series ages (referred to herein as 'conventional U-series ages') that would otherwise be discarded into open-system U-series model ages (Scholz et al., 2004; Thompson et al., 2003; Villemant and Feuillet, 2003). However, the reliability of open-system Useries model ages is still heavily debated, primarily due to secondary open-system shifts that are not accounted for by the model corrections together with a limited knowledge of the seawater $\delta^{234} \mathrm{U}$ in the past.

The above issues have limited the number of well-dated fossil coral observations beyond MIS 5.5, although there are a growing number of data points for MIS 6, MIS 7 and MIS 9 (e.g. Ayling et al., 2006; Bard et al., 1996b; Camoin et al., 2001; Galewsky et al., 1996; Gallup et al., 1994; Scholz et al., 2006; Stirling et al., 2001; Thomas et al., 2009; Thompson and Goldstein, 2005). In this study, we have applied very high-precision U-series methods to fossil coral reefs formed at Henderson Island during MIS 7 (245$230 \mathrm{ka})$ and 9 (339-303 ka). This investigation extends previously published U-series studies for Henderson Island, which studied fossil reefs formed during MIS 9 and 15 (Andersen et al., 2008; Stirling et al., 2001).

\section{LOCALITY AND SAMPLES}

Henderson Island, part of the Pitcairn Island Group, is a fossil coral atoll located at $24.2^{\circ} \mathrm{S}$ and $128.2^{\circ} \mathrm{W}$ in the South Pacific Ocean (Fig. 1). Quaternary volcanic activity on nearby Pitcairn Island (Duncan et al., 1974), located $\sim 200 \mathrm{~km}$ to the south-southwest, is believed to have resulted in the slow and systematic uplift of Henderson Island by volcanic loading and bulge rebound processes related to lithospheric flexure (McNutt and Menard, 1978). Volcanic activity on Pitcairn Island has evidently occurred as several discrete episodes within the last million years from $\sim 430$ to $\sim 850$ ka based on K-Ar dating (Duncan et al., 1974). Constraining the uplift history of Henderson Island is therefore, non-trivial, requiring lithospheric flexural and isostatic rebound modelling, although a total net uplift of $55 \pm 12 \mathrm{~m}$ since $\sim 600 \mathrm{ka}$ has been estimated based on the U-series dating of fossil corals (Andersen et al., 2008). Detailed descriptions of the carbonate geomorphology of Henderson Island have been published previously (Blake, 1995; Pandolfi, 1995). Henderson Island is remotely located at the southeast margin of the Indo-Pacific subtropical belt, which makes any coral reef formation very sensitive to climatic and ecological changes (Andersen et al., 2008; Ayling et al., 2006; Benton and Spencer, 1995; Stirling et al., 2001). This implies that several environmental criteria must be fulfilled in order for prolific coral growth to occur on the island. Specifically, the ability to transport coral larvae to Henderson Island via island jumping from the north-western pacific islands is required to initiate and sustain prolific coral reef development, even if marine surface-water temperatures are sufficiently high to trigger widespread coral growth (Irving, 1995; Paulay, 1989). Coral reefs at Henderson Island are presently sparse spatially and in diversity (Blake, 1995; Irving, 1995) and the range of water depths in which modern coral species are observed to grow is not well constrained. Additionally, significant coral species turnover between the modern and the fossil record further complicates this estimate (Irving, 1995). However, observational data from Tahiti, also in the central Pacific Ocean, suggests that branching Acropora, and to some extent massive Porites, in combination with domed-shaped Faviid corals, grow in limited water depths of $<6 \mathrm{~m}$ (Cabioch et al., 1999). Similar water depths have been inferred for fossil coral growth in the entire Indo-Pacific region (Montaggioni, 2005) and are also considered valid for Henderson Island in the present study. The fossil record shows that reefs grew prolifically on Henderson Island during MIS 15, MIS 9, and to a lesser extent, MIS 7. Given the above issues, we consider it likely that these paleo-reefs correlate with warm periods of stable sea-level, allowing sufficient time for a well-developed reef structure to form.

Earlier U-series dating of fossil corals from Henderson Island was conducted on samples collected during the 1990-1991 Pitcairn Scientific Expedition and provides a framework for understanding reef development on the island. Specifically, U-series observations for well preserved fossil corals sampled along several transects suggest the initial development of a fossil lagoon at ca. $600 \mathrm{ka}$ during MIS 15 and possibly earlier, followed by major prolific fringing reef development at 325-320 ka correlated with MIS 9.3. This was most likely followed by minor reef development at 310-305 ka during MIS 9.1 (Stirling et al., 2001). To further investigate the timing of past sea-level events recorded on Henderson Island, additional fossil corals were collected during a subsequent expedition to the island in 2003 (Andersen et al., 2008; Ayling et al., 2006). Fossil corals were collected from outcrops in the fossil lagoon, and from reef terraces at the East and North beaches, and included the sampling of a North Beach drill core, extending $\sim 20 \mathrm{~m}$ below the base of the present day beach rock surface (Fig. 1). High-precision $\mathrm{U}$-series dating of fossil corals sampled from the $>500 \mathrm{ka}$ fossil lagoon, using identical techniques to those employed in the present study, was conducted in a recent study by Andersen 

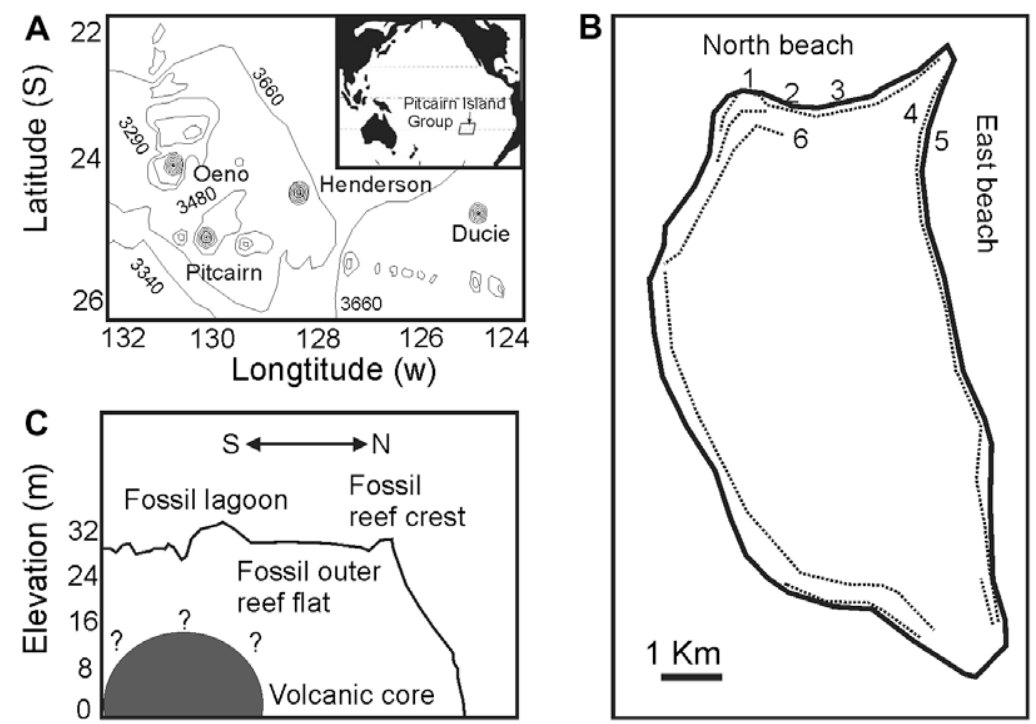

Fig. 1. (A) Map showing the location of Henderson Island in the South Pacific Ocean. (B) Arial overview of Henderson Island; stippled lines indicate steep cliffs $(>10 \mathrm{~m}$ ), which surround the island. The numbers refer to the sample units listed in Table 1 as follows: (1) NB-D; (2) NBA, NB-B and the drill core site; (3) NB-C; (4) FL-G; (5) EB-E and NEB; (6) FL and NFL. (C) Schematic cross-section of Henderson Island. Modified from Stirling et al. (2001) and Blake (1995).

et al. (2008). In particular, several independent measurements of a well-preserved coral gave a U-series age of $600 \pm 15 \mathrm{ka}$, and most likely correlates with the MIS 15.5 interglacial period (Andersen et al., 2008). The MIS 15 origin of many of the corals was also evidenced by applying the open-system U-series model of Thompson et al. (2003) (TSG\&S) to the U-series results for diagenetically altered samples. Open-system model results also suggest an older origin (MIS 17) for some fossil corals, which requires further confirmation.

In this study, fossil corals from the North Beach, East Beach and the fossil lagoon, previously associated with MIS 9 and 7.5 fringing reef development, were targeted for U-series dating (Table 1, Fig. 2). All fossil corals were collected in growth position, with the exception of those recovered from the drill-core (samples LC-1 and 2). All fossil coral heights are referenced to present day Mean Sea Level (MSL), located approximately one meter above the Mean Low Water Springs (MLWS) reference datum at Henderson Island.

\section{ANALYTICAL PROTOCOLS}

\subsection{Sample pre-selection and preparation}

Coral samples were prepared for analysis using a diamond drill as either whole "bulk" fragments (e.g. for Faviidae and Porites species) or, where possible, by separating out the dense "wall" fragments from the porous septa parts for the thick-walled species (e.g. for Faviidae corals) (Andersen et al., 2008; Stirling et al., 1995). Samples were inspected in thin section to investigate the presence of secondary alteration textures, and the detection of secondary calcite recrystallization and infilling was achieved using X-Ray Diffraction (XRD) measurement techniques (with a $1 \%$ calcite detection limit). The majority of targeted corals fulfilled the criteria of retaining their primary aragonitic textures and having no detectable calcite. In situ laser-ablation (LA)-MC-ICPMS measurements of the U-series isotopes were then conducted on the majority of fossil corals using a $193 \mathrm{~nm}$ ArF excimer laser ablation system coupled to a Nu Plasma MC-ICPMS (Nu Instruments, UK) at the ETH, Zürich and methods described in Potter et al. (2005b). Although relatively imprecise, the LA-MC-ICPMS technique enables coral samples to be rapidly screened out on the basis of anomalous U-series isotopic compositions using the a posteriori criteria outlined in Section 1, thus bypassing the need to perform time-consuming chemical processing on altered samples that would afterwards be rejected.

\subsection{U-series MC-ICPMS measurements}

Solution nebulization MC-ICPMS measurements of the $\mathrm{U}$-series isotopes were conducted on pre-selected samples using a $\mathrm{Nu}$ Instruments $\mathrm{Nu}$ Plasma MC-ICPMS at the ETH, Zürich and multiple-Faraday cup protocols reported previously in Andersen et al. (2004, 2007, 2008), Potter et al. (2005a) and Stirling et al. (2006, 2007). A full explanation of the spike calibration and chemical separation and purification protocols can be found in Andersen et al. (2008) and Potter et al. (2005a). The multiple-Faraday cup approach yields significantly better analytical performance compared with the conventional use of less stable ion counter devices for the measurement of the minor ${ }^{234} \mathrm{U}$ and ${ }^{230} \mathrm{Th}$ isotopes. Using this approach, carbonate standards can be measured with a long-term reproducibility of $\pm 0.3 \%$ and $\pm 0.4 \%$ o $(2 \sigma)$ for ${ }^{234} \mathrm{U} /{ }^{238} \mathrm{U}$ and ${ }^{230} \mathrm{Th} /{ }^{238} \mathrm{U}$, respectively (Andersen et al., 2004, 2008; Potter et al., 2005a). This represents at least a factor of three improve- 
Table 1

Locality description.

North Beach (NB)

Unit A

Reef unit NB-A is located at the base of a steep cliff section and is dominated by a massive carbonate matrix, occasionally interspersed with fossil corals (e.g. Montastria sample NB-A-6). Most of the fossil corals within this reef unit are heavily calcified. A 20 m drill core section recovered from this site extends from the surface, located at $\sim 6 \mathrm{~m}$ above present mean sea-level (MSL), to $\sim 14 \mathrm{~m}$ below MSL

Unit B

Reef unit NB-B is a minor draping reef unit, which overlies a well-cemented and well-lithified massive limestone interspersed with poorly preserved corals (Acropora). This unit is not stratigraphically connected to any larger reef unit (Fig. 2)

Unit $C$

Although less extensive and less well-defined, reef unit NB-C comprises similar domed-shaped Faviidae corals interspersed with less abundant Porites corals occurring at the same stratigraphic height as observed in reef unit NB-D

Unit D

Reef unit NB-D is dominated by dome-shaped Faviidae coral heads extending to $\sim 1 \mathrm{~m}$ in diameter, interspersed with less abundant, but similarly-sized Porites corals, encrusted with species of platey corals. These corals are located within a zone occurring $\sim 4-6 \mathrm{~m}$ above present MSL (Fig. 2). The surrounding carbonate matrix consists of massive limestone with interstitial coral fragments and echinoderm spines. The upper section of this profile has a zone of horizontal-branching acropora corals (Fig. 2), which have experienced alteration in the form of extensive calcification. The geomorphology suggests that the Acropora formed contemporaneously with the rest of the outcrop

East Beach

Unit $E$

Cliff transect extending from beach level at $\sim 4 \mathrm{~m}$ above present MSL to $\sim 20 \mathrm{~m}$ above present MSL. This profile includes spur and groove topography and poorly lithified, horizontally stratified conglomerates. Most fossil corals within this unit show signs of alteration, especially as secondary calcite replacement of the primary aragonitic coral skeleton. Therefore, only a limited number of samples from this reef unit were selected for U-series dating purposes

Unit $F$

Reef unit F consists of a well-defined paleo-fringing reef unit dominated by massive Porites and Faviidae dome-shaped corals (see Ayling et al. (2006) for a more detailed description of this reef unit)

Fossil lagoon

Unit $G$

Fossil lagoon transect extending across the paleo-reef plateau between the East and North beaches at an elevation of $\sim 20 \mathrm{~m}$ above present MSL. The majority of fossil corals outcropping along this transect are heavily calcified

Unit $H$

NFL and FL fossil lagoon transects reported in Andersen et al. (2008). Fossil coral NFL-40 was sampled $\sim 100 \mathrm{~m}$ from the northern margin of the outer reef slope of the fossil reef crest. $>500 \mathrm{ka}$ fossil corals reported in Andersen et al. (2008) were collected nearby

ment in analytical precision compared with conventional measurements using ion counting devices. For example, in $300 \mathrm{ka}$ corals, $2 \sigma$ age uncertainties are significantly reduced from $\pm 4 \mathrm{ka}$ to better than $\pm 1 \mathrm{ka}$, and the errors associated with $\delta^{234} \mathrm{U}_{\mathrm{i}}$ are reduced from $\pm 4-10 \%$ to $\pm 1-2 \%(2 \sigma)$ using multiple-Faraday cup techniques.

\section{RESULTS}

Fifty high-precision U-series ages for 32 different fossil corals sampled from Henderson Island's reefs were measured in this study (Table 2). These data are presented together with previously published U-series results for Henderson Island in Fig. 3. Taken together, these data roughly cluster into three main groupings, with U-series ages centered around $\sim 600 \mathrm{ka}$ (MIS 15), $300 \mathrm{ka}$ (MIS 9) and $\sim 240 \mathrm{ka}$ (MIS 7).

\subsection{Observations of U-series open-system behaviour}

Despite efforts to detect alteration processes based on macroscopic criteria, it is evident that significant post-depositional open-system behaviour of the U-series isotopes has occurred in many of the analyzed samples (Figs. 3-5). As discussed in Section 1, a first order indication of the extent to which open-system behaviour has affected the sample can be obtained by comparing its initial $\delta^{234} U_{\mathrm{i}}$ at the time of growth against the $\delta^{234} \mathrm{U}$ of modern seawater. In a plot of $\left[{ }^{230} \mathrm{Th} /{ }^{238} \mathrm{U}\right]_{\text {act }}$ versus $\delta^{234} \mathrm{U}$, this comparison can be made by comparing the coral's present day $\delta^{234} U$ with the composition of the 'seawater evolution curve', assuming a constant open-ocean $\delta^{234} U$ of $147 \%$ as a first order constraint (Stirling and Andersen, 2009). This approach provides a means of detecting gross violation of the closed-system assumption, but may be unsuitable for detecting subtle levels of open-system exchange of the $\mathrm{U}$-series isotopes, especially if the $\delta^{234} \mathrm{U}$ composition of seawater has varied through time. For the Henderson Island data, U-series open-system behaviour is largely manifested by a correlated shift in $\left[{ }^{230} \mathrm{Th} /{ }^{238} \mathrm{U}\right]_{\text {act }}$ and $\delta^{234} \mathrm{U}$ towards elevated values, forming a broadly linear array trending away from the seawater evolution curve, as has been observed at other fossil reef localities (e.g. Gallup et al., 1994; Stirling et al., 1998). However, in some corals, a relative enrichment or depletion in $\left[{ }^{230} \mathrm{Th} /{ }^{238} \mathrm{U}\right]_{\text {act }}$ is superimposed on these sub-linear alteration trends as a secondary 

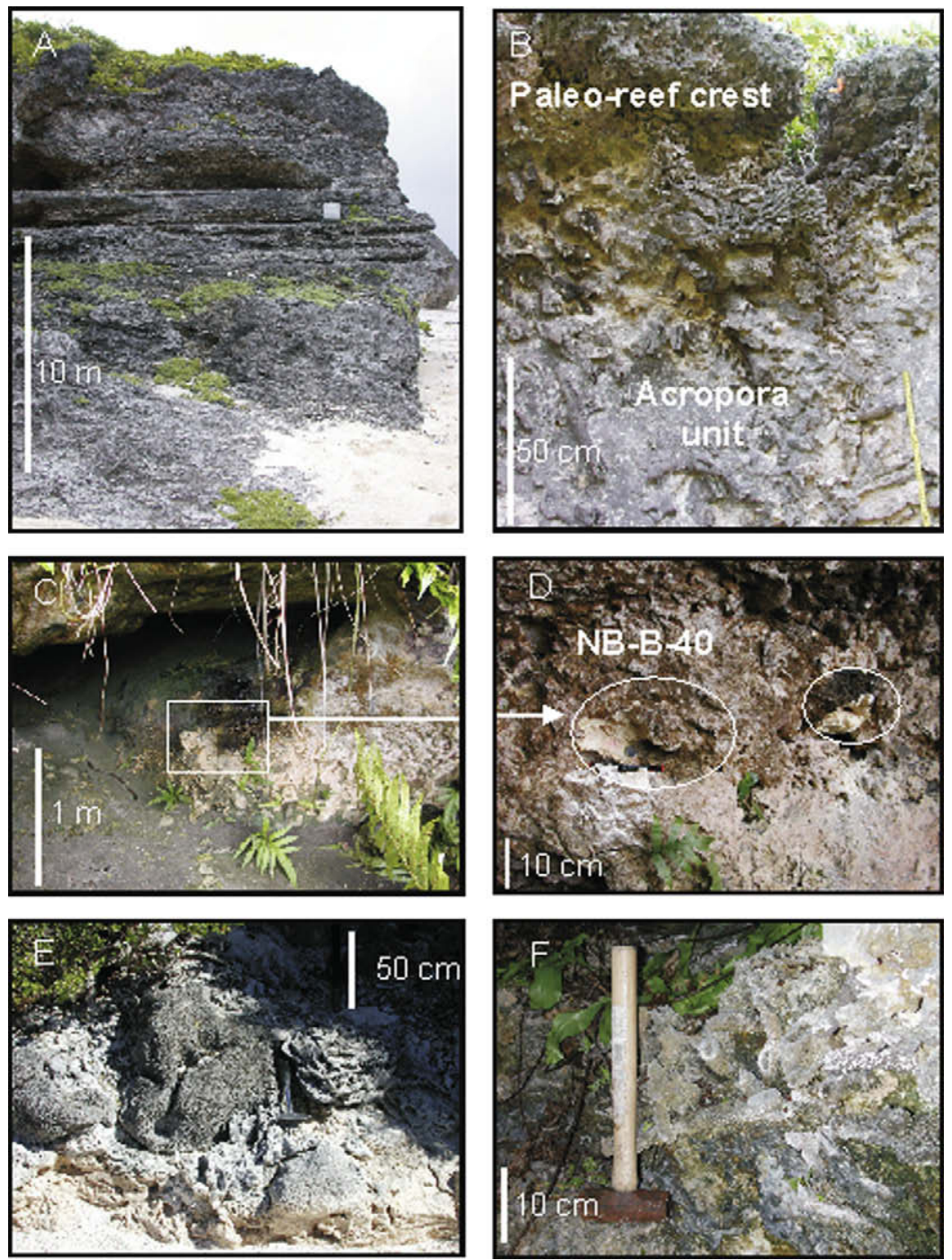

Fig. 2. (A) Profile of a cliff section at East Beach, Henderson Island, extending from $\sim 5 \mathrm{~m}$ to $\sim 20 \mathrm{~m}$ above present MSL at the top of the island. A horizontal paleo-beach rock bench unit is overlain by cave formations at $\sim 15 \mathrm{~m}$ above present MSL around the entire perimeter of the island. The contact between these two geomorphological features at $\sim 15 \mathrm{~m}$ is believed to represent a paleo-sea-level marker for the MIS 5.5 or 7.1 sea-level high-stand (Blake, 1995). (B) Top of the cliff section at North Beach, outcropping to $\sim 28 \mathrm{~m}$ above present MSL. The reef unit shown is believed to represent a paleo-reef crest, dominated by altered branching coral species and cemented coral rubble. A distinct unit comprising horizontal branching Acropora corals in a massive carbonate matrix is located $\sim 2 \mathrm{~m}$ below the reef crest (not dated). The top of the island represents a sub-horizontal paleo-reef flat, which extends inland from the coastal sections. The Acropora unit most likely represents a fossil reef formed in a high-energy environment contemporaneously with reef crest development during a paleo-sea-level high-stand occurring either prior to or during MIS 9. (C) Unit NB-B on North Beach. Fossil corals were collected from a minor draping reef unit at the base of the cliff section from $\sim 8 \mathrm{~m}$ above present MSL. (D) Fossil corals located in growth position within reef unit NB-B. Two Montastria fossil corals are highlighted, including sample NB-B-40, which is $\sim 20 \mathrm{~cm}$ in diameter and was targeted for U-series dating. (E) The lowermost section of the extensive NB-D reef unit, situated at the base of the cliff section at the western margin of North Beach. This reef unit is dominated by large dome-shaped Faviidae coral heads up to $1 \mathrm{~m}$ in diameter, interspersed with similar-sized but less frequent Porites corals. (F) Horizontal branching Acropora corals overlying the NB-D Faviidae-dominated unit shown in E. These Acropora corals are heavily calcified and are not suitable for U-series dating.

shift without noticeably disturbing the $\delta^{234} U$ composition (Fig. 5). Detailed observations of the U-series ages, $\delta^{234} U_{i}$ and secondary open-system trends are discussed below.

\subsubsection{Porites coral species}

By comparing the U-series measurements of Porites and Faviidae coral species, it is evident that Porites species have experienced a greater degree of U-series open-system behaviour than Faviidae corals sampled from the same reef unit, consistent with observations at other localities (Esat et al., 1999; Stirling et al., 1995). For example, Porites sample NB-D-3 from Unit D (Table 2) has a very elevated $\left.{ }^{230} \mathrm{Th} /{ }^{238} \mathrm{U}\right]_{\text {act }}$ that is offset by ca. $+5 \%$ and a $\delta^{234} \mathrm{U}$ that is shifted by ca. $+1 \%$ with respect to values obtained for Faviidae corals from the same reef unit, which generally have conventional $\mathrm{U}$-series ages centered about $\sim 330 \mathrm{ka}$ 
Table 2

$\mathrm{U}-\mathrm{Th}$ isotope ratios and U-series ages for Henderson Island fossil corals

\begin{tabular}{|c|c|c|c|c|c|c|c|c|c|c|c|c|c|c|c|c|c|}
\hline Sample $^{\mathrm{a}}$ & $-\mathrm{b}$ & ${ }_{-}^{\mathrm{c}}$ & ${ }_{-}^{\mathrm{d}}$ & $\mathrm{MSL}^{\mathrm{e}}$ & $\begin{array}{l}{ }^{232} \mathrm{Th}^{\mathrm{f}} \\
(\mathrm{ppb})\end{array}$ & $\begin{array}{l}{ }^{238} \mathrm{U}^{\mathrm{g}} \\
(\mathrm{ppm})\end{array}$ & $\pm 2 \sigma$ & \multicolumn{2}{|c|}{$\delta^{234} \mathrm{U}^{\mathrm{h}}$} & \multicolumn{2}{|c|}{$\left[{ }^{230} \mathrm{Th} /{ }^{238} \mathrm{U}\right]_{\mathrm{act}}^{\mathrm{h}}$} & \multicolumn{2}{|c|}{ Age $(\mathrm{ka})^{\mathrm{i}}$} & \multicolumn{2}{|c|}{$\delta^{234} \mathrm{U}_{\mathrm{i}}^{\mathrm{j}}(\%)$} & \multicolumn{2}{|c|}{$\mathrm{O}-\mathrm{S}$ age $(\mathrm{ka})^{\mathrm{k}}$} \\
\hline \multicolumn{18}{|c|}{ NORTH BEACH } \\
\hline NB-A-6A & WP & $\mathrm{F}$ & $>99$ & 8 & 0.01 & 1.84 & 0.09 & 22.4 & 0.3 & 1.0281 & 0.0009 & 617 & $28(28)$ & 128 & 10 & 647 & 16 \\
\hline NB-A-6B & WP & $\mathrm{F}$ & $>99$ & 8 & 0.01 & 2.04 & 0.05 & 21.2 & 0.3 & 1.0344 & 0.0007 & - & & - & & 811 & 41 \\
\hline$L C-1$ & $W P$ & $F$ & - & -17 & $<0.00$ & 2.15 & 0.05 & 27.1 & 0.3 & 1.0226 & 0.0005 & 462.7 & $4.5(4.7)$ & 100.1 & 1.7 & 521.5 & 5.2 \\
\hline $\begin{array}{l}L C-2 \\
\text { Unit B }\end{array}$ & Bulk & $A$ & - & -9 & 0.01 & 2.80 & 0.03 & 13.8 & 0.3 & 1.0123 & 0.0018 & 540.8 & $28(28)$ & 63.8 & 5.2 & 697 & 30 \\
\hline$N B-B-40 A$ & $W P$ & $F$ & $>99$ & 8 & $<0.00$ & 2.49 & 0.12 & 74.7 & 0.3 & 0.9224 & 0.0003 & 203.1 & $0.3(0.6)$ & 132.6 & 0.6 & 210.1 & 2.1 \\
\hline NB-B-40B & WP & $\mathrm{F}$ & $>99$ & 8 & $<0.00$ & 2.59 & 0.13 & 74.3 & 0.3 & 0.9735 & 0.0005 & 240.6 & $0.5(0.8)$ & 146.7 & 0.7 & 240.7 & 0.7 \\
\hline NB-B-40C(1) & WP & $\mathrm{F}$ & $>99$ & 8 & $<0.00$ & - & - & 74.5 & 0.3 & 0.9733 & 0.0005 & 240.1 & $0.5(0.8)$ & 147.0 & 0.7 & 240.1 & 0.7 \\
\hline NB-B-40C(2) & WP & $\mathrm{F}$ & $>99$ & 8 & $<0.00$ & - & - & 74.3 & 0.3 & 0.9729 & 0.0005 & 240.0 & $0.5(0.8)$ & 146.3 & 0.7 & 240.3 & 0.8 \\
\hline $\begin{array}{l}\text { NB-B-40(D) } \\
\text { Unit C }\end{array}$ & Bulk & $\mathrm{F}$ & $>99$ & 8 & 0.01 & 2.37 & 0.06 & 75.4 & 0.3 & 0.9783 & 0.0004 & 243.6 & $0.5(0.8)$ & 150.1 & 0.7 & 241.9 & 0.7 \\
\hline$N B-C-1 A$ & $W P$ & $F$ & $>99$ & 5 & 0.01 & 2.30 & 0.12 & 76.3 & 0.3 & 0.9000 & 0.0004 & 189.1 & $0.3(0.6)$ & 130.3 & 0.6 & 196.9 & 2.5 \\
\hline NB-C-1B & WP & $\mathrm{F}$ & $>99$ & 5 & 0.01 & - & - & 76.2 & 0.3 & 0.9676 & 0.0004 & 233.8 & $0.4(0.8)$ & 147.6 & 0.6 & 233.5 & 0.7 \\
\hline NB-C-1C & WP & $\mathrm{F}$ & $>99$ & 5 & $<0.00$ & - & - & 76.4 & 0.3 & 0.9698 & 0.0004 & 235.4 & $0.4(0.8)$ & 148.6 & 0.6 & 234.6 & 0.7 \\
\hline NB-C-1D & WP & $\mathrm{F}$ & $>99$ & 5 & 0.01 & - & - & 76.0 & 0.3 & 0.9688 & 0.0006 & 235.0 & $0.6(0.8)$ & 147.6 & 0.7 & 234.7 & 0.7 \\
\hline NB-C-1E & Bulk & $\mathrm{F}$ & - & 5 & 0.01 & - & - & 75.6 & 0.3 & 0.9730 & 0.0006 & 238.7 & $0.6(0.9)$ & 148.5 & 0.7 & 237.9 & 0.7 \\
\hline NB-C-2 & WP & $\mathrm{F}$ & $>99$ & 5 & 0.01 & 2.41 & 0.12 & 78.9 & 0.3 & 0.9786 & 0.0004 & 240.4 & $0.4(0.8)$ & 155.7 & 0.7 & 235.6 & 0.9 \\
\hline NB-C-3A & WP & $\mathrm{F}$ & $>99$ & 5 & $<0.00$ & 1.99 & 0.05 & 63.9 & 0.3 & 1.0329 & 0.0005 & 331.2 & $1.3(1.5)$ & 162.9 & 1.0 & 319.8 & 2.9 \\
\hline $\begin{array}{l}\text { NB-C-3B } \\
\text { Unit D }\end{array}$ & WP & $\mathrm{F}$ & $>99$ & 5 & $<0.00$ & 2.08 & 0.10 & 64.7 & 0.3 & 1.0290 & 0.0004 & 322.0 & $1.0(1.3)$ & 160.7 & 0.9 & 312.3 & 2.4 \\
\hline$N B-D-1 A$ & $W P$ & $F$ & $>99$ & 5 & 0.01 & 2.19 & 0.11 & 63.7 & 0.3 & 0.9654 & 0.0004 & 244.0 & $0.5(0.8)$ & 126.9 & 0.7 & 255.5 & 2.4 \\
\hline NB-D-1B & WP & $\mathrm{F}$ & $>99$ & 5 & $<0.00$ & 2.04 & 0.05 & 63.6 & 0.3 & 1.0289 & 0.0005 & 324.5 & $1.1(1.4)$ & 159.0 & 1.0 & 315.9 & 2.3 \\
\hline NB-D-1C & WP & $\mathrm{F}$ & $>99$ & 5 & $<0.00$ & - & - & 63.0 & 0.3 & 1.0296 & 0.0005 & 326.9 & $1.2(1.4)$ & 158.8 & 1.0 & 318.5 & 2.3 \\
\hline NB-D-1D & WP & $\mathrm{F}$ & $>99$ & 5 & $<0.00$ & - & - & 62.8 & 0.3 & 1.0290 & 0.0005 & 326.3 & $1.2(1.4)$ & 157.9 & 1.0 & 318.5 & 2.2 \\
\hline NB-D-1E & Bulk & $\mathrm{F}$ & $>99$ & 5 & 0.01 & - & - & 63.9 & 0.3 & 1.0438 & 0.0005 & 354.7 & $1.6(1.9)$ & 174.1 & 1.2 & 334.1 & 4.9 \\
\hline NB-D-2 & WP & $\mathrm{F}$ & $>99$ & 5 & $<0.00$ & 2.13 & 0.11 & 65.4 & 0.3 & 1.0346 & 0.0004 & 330.7 & $1.1(1.4)$ & 166.6 & 1.0 & 316.6 & 3.3 \\
\hline NB-D-3 & Bulk & $\mathrm{P}$ & $>99$ & 5 & 0.07 & 2.98 & 0.07 & 72.9 & 0.3 & 1.0998 & 0.0004 & & & & 16 & & 10 \\
\hline NB-D-4 & WP & $\mathrm{F}$ & $>99$ & 5 & $<0.00$ & 2.18 & 0.11 & 63.7 & 0.3 & 1.0333 & 0.0004 & 332.5 & $1.1(1.4)$ & 162.9 & 1.0 & 321.0 & 2.9 \\
\hline NB-D-5 & WP & $\mathrm{F}$ & $>99$ & 5 & $<0.00$ & 2.03 & 0.10 & 64.5 & 0.3 & 1.0315 & 0.0006 & 327.1 & $1.4(1.6)$ & 162.6 & 1.0 & 0 & 2.9 \\
\hline$N B-D-6$ & $W P$ & $F$ & $>99$ & 5 & 0.01 & 2.03 & 0.10 & 64.5 & 0.3 & 0.9846 & 0.0004 & 261.9 & $0.6(0.9)$ & 135.2 & 0.7 & 269.0 & 1.6 \\
\hline NB-D-7 & WP & $\mathrm{F}$ & $>99$ & 5 & $<0.00$ & 2.20 & 0.11 & 64.0 & 0.3 & 1.0335 & 0.0004 & 332.2 & $1.1(1.4)$ & 163.6 & 1.0 & 320.2 & 3.0 \\
\hline NB-D-8 & WP & $\mathrm{F}$ & $>99$ & 5 & 0.01 & 2.10 & 0.10 & 65.6 & 0.3 & 1.0401 & 0.0004 & 341.5 & $1.3(1.5)$ & 172.2 & 1.0 & 323.0 & 4.3 \\
\hline $\begin{array}{l}\text { EAST BEA } \\
\text { Unit E }\end{array}$ & & & & & & & & & & & & & & & & & \\
\hline EB-E-11 & WP & $\mathrm{F}$ & $>99$ & 12 & 0.01 & 2.39 & 12 & 74.1 & & 0561 & 0.0005 & 2.5 & 1.5( & 200.7 & 1.2 & & 8.4 \\
\hline EB-E-1 & WP & $\mathrm{F}$ & $>99$ & 5 & 0.01 & 2.27 & 0.11 & 78.0 & 0.3 & 1.0720 & 0.0005 & 380.3 & $2.0(2.1)$ & 228.6 & 1.6 & 324.2 & 4.3 \\
\hline $\begin{array}{l}\text { EB-E-2 } \\
\text { Unit F }\end{array}$ & WP & $\mathrm{F}$ & $>99$ & 14 & 0.01 & 2.36 & 0.06 & 67.2 & 0.3 & 1.0420 & 0.0004 & 340.9 & $1.2(1.5)$ & 176.2 & 1.0 & 319.7 & 4.8 \\
\hline$N E B-1 A$ & Bulk & $P$ & $>99$ & 5 & 0.07 & 2.51 & 0.13 & 89.8 & 0.3 & 0.9559 & 0.0004 & 214.3 & $0.4(0.7)$ & 164.5 & 0.6 & 205.6 & 0.8 \\
\hline$N E B-1 B$ & Bulk & $P$ & $>99$ & 5 & 0.06 & 2.80 & 0.14 & 70.1 & 0.3 & 0.9425 & 0.0004 & 219.7 & $0.4(0.7)$ & 130.5 & 0.6 & 228.3 & 2.2 \\
\hline$N E B-1 C$ & Bulk & $P$ & $>99$ & 5 & 0.03 & 2.45 & 0.12 & 72.6 & 0.3 & 0.9714 & 0.0004 & 240.4 & $0.4(0.8)$ & 143.2 & 0.7 & 242.5 & 0.9 \\
\hline$N E B-3$ & Bulk & $P$ & $>99$ & 5 & 0.05 & 2.49 & 0.12 & 89.6 & 0.3 & 0.9218 & 0.0005 & 193.7 & $0.3(0.6)$ & 154.9 & 0.6 & 189.9 & 0.4 \\
\hline NEB-2A(1) & WP & $\mathrm{F}$ & $>99$ & 5 & $<0.00$ & 2.00 & 0.10 & 73.5 & 0.3 & 1.0498 & 0.0004 & 340.6 & $1.2(1.5)$ & 192.4 & 1.1 & & 6.9 \\
\hline NEB-2A(2) & WP & $\mathrm{F}$ & $>99$ & 5 & $<0.00$ & - & - & 73.5 & 0.3 & 1.0494 & 0.0006 & 339.8 & $1.5(1.8)$ & 191.9 & 1.2 & & 6.9 \\
\hline NEB 2B & WP & $\mathrm{F}$ & $>99$ & 5 & $<0.00$ & 1.98 & 0.05 & 75.7 & 0.3 & 1.0476 & 0.0008 & 330.5 & $1.6(1.8)$ & 192.8 & 1.2 & 299.1 & 6.7 \\
\hline NEB-4(1) & WP & $\mathrm{F}$ & $>99$ & 5 & $<0.00$ & 1.93 & 0.10 & 80.3 & 0.3 & 1.0550 & 0.0005 & 333.6 & $1.3(1.5)$ & 206.1 & 1.1 & 293.5 & 8.4 \\
\hline NEB-4(2) & WP & $\mathrm{F}$ & $>99$ & 5 & $<0.00$ & - & - & 79.9 & 0.3 & 1.0548 & 0.0005 & 334.3 & $1.3(1.5)$ & 205.5 & 1.1 & 294.5 & 8.4 \\
\hline NEB 5 & WP & $\mathrm{F}$ & $>99$ & 5 & $<0.00$ & 1.84 & 0.05 & 87.1 & 0.3 & 1.0818 & 0.0005 & 374.5 & $1.8(1.9)$ & 251.0 & 1.6 & 306.6 & 4.9 \\
\hline $\begin{array}{l}\text { FOSSIL LA } \\
\text { Unit } \mathrm{G}\end{array}$ & $\mathrm{DN}$ & & & & & & & & & & & & & & & & \\
\hline FL-G-1 & WP & $\mathrm{F}$ & - & 20 & 0.03 & 2.06 & 0.05 & 45.0 & 0.5 & 1.0677 & 0.0006 & - & & - & & 542 & 14 \\
\hline $\begin{array}{l}\text { FL-G-2 } \\
\text { Unit H }\end{array}$ & WP & $\mathrm{F}$ & - & 20 & 0.02 & 1.96 & 0.05 & 22.4 & 0.3 & 1.0502 & 0.0012 & - & & - & & - & \\
\hline NFL40 & WP & $\mathrm{F}$ & $>99$ & 28 & 0.03 & 2.31 & 0.12 & 70.9 & 0.3 & 1.0623 & 0.0006 & 379.5 & $2.1(2.2)$ & 207.2 & 1.5 & 336.6 & 3.6 \\
\hline $\begin{array}{l}\text { Samples repc } \\
\text { in Stirling et }\end{array}$ & d & & & & & & & & & & & & & & & & \\
\hline Hen 1.6 & WP & A & - & 1 & 0.01 & 2.08 & 0.10 & 67.6 & 0.3 & 1.0340 & 0.0004 & 324.5 & $1.0(1.3)$ & 169.0 & 0.9 & 309.1 & 3.4 \\
\hline Hen 1.23 & WP & $\mathrm{M}$ & - & 20 & 0.01 & 1.89 & 0.09 & 70.2 & 0.3 & 1.0393 & 0.0006 & 328.0 & $1.3(1.5)$ & 177.5 & 1.0 & 306.7 & 4.6 \\
\hline Hen 1.26 & WP & $\mathrm{M}$ & - & 26 & 0.01 & 2.39 & 0.06 & 66.7 & 0.3 & 1.0355 & 0.0005 & 329.3 & $1.1(1.4)$ & 169.2 & 1.0 & 313.6 & 3.6 \\
\hline
\end{tabular}


Table 2 (continued)

\begin{tabular}{|c|c|c|c|c|c|c|c|c|c|c|c|c|c|c|c|}
\hline \multirow[t]{2}{*}{ Sample $^{a}$} & \multirow[t]{2}{*}{$-{ }^{\mathrm{b}}$} & \multirow[t]{2}{*}{$-^{\mathrm{c}}-^{\mathrm{d}} \mathrm{MSL}^{\mathrm{e}}$} & \multirow{2}{*}{$\begin{array}{l}{ }^{232} \mathrm{Th}^{\mathrm{f}} \\
(\mathrm{ppb})\end{array}$} & \multirow{2}{*}{$\begin{array}{l}{ }^{238} \mathrm{U}^{\mathrm{g}} \\
(\mathrm{ppm}) \\
\end{array}$} & \multicolumn{3}{|c|}{$\delta^{234} U^{h}$} & \multirow{2}{*}{\multicolumn{2}{|c|}{$\begin{array}{c}\left.{ }^{230} \mathrm{Th} /{ }^{238} \mathrm{U}\right]_{\mathrm{act}}^{\mathrm{h}} \\
\pm 2 \sigma\end{array}$}} & \multirow{2}{*}{\multicolumn{2}{|c|}{$\begin{array}{r}\text { Age }(\mathrm{ka})^{\mathrm{i}} \\
\pm 2 \sigma\end{array}$}} & \multirow{2}{*}{\multicolumn{2}{|c|}{$\begin{array}{r}\delta^{234} U_{\mathrm{i}}^{\mathrm{j}}(\% \mathrm{o}) \\
\pm 2 \sigma \\
\end{array}$}} & \multirow{2}{*}{\multicolumn{2}{|c|}{$\begin{array}{r}\text { O-S age(ka) } \\
\pm 2 \sigma \\
\end{array}$}} \\
\hline & & & & & $\pm 2 \sigma$ & $(\%)$ & $\pm 2 \sigma$ & & & & & & & & \\
\hline & $\mathrm{B}$ & -18 & 0.03 & 2.56 & 0.06 & 64.7 & 0.3 & 1.0301 & 0.0009 & 324.0 & $1.8(2.0)$ & 161.6 & $\begin{array}{ll}6 & 1.1\end{array}$ & 313.7 & 2.9 \\
\hline FH 350 & WP & $F-24$ & $<0.00$ & 2.16 & 0.11 & 68.0 & 0.3 & 1.0378 & 0.0007 & 330.5 & $1.6(1.8)$ & 173.2 & 21.1 & 312.0 & 4.3 \\
\hline FH 328 & WP & $F-24$ & 0.01 & 1.88 & 0.09 & 18.1 & 0.3 & 1.0266 & 0.0007 & - & & - & & 782 & 27 \\
\hline
\end{tabular}

Other samples

Oeno, modern Porites

146.80 .3

Ground water (Unit A)

$\begin{array}{ll}70.4 & 1.0\end{array}$

Bulk carbonate matrix (Unit A)

$63.2 \quad 1.0$

Samples from other

localities

RN-FB-7, Rottness Island,

Western Australia (different

subsamples, wall parts)

This study

Stirling et al. (2001)

$\begin{array}{lllllll}\mathbf{1 0 4 . 8} & \mathbf{0 . 3} & \mathbf{0 . 7 7 0 4} & \mathbf{0 . 0 0 0 7} & \mathbf{1 2 6 . 8} & \mathbf{0 . 2} \\ 104.8 & 0.9 & 0.7739 & 0.0018 & 127.8 & 0.6 \\ 105.3 & 1.2 & 0.7702 & 0.0005 & 126.6 & 0.3 \\ 105.9 & 1.4 & 0.7766 & 0.0007 & 128.4 & 0.4 \\ 106.4 & 0.6 & 0.7717 & 0.0006 & 126.8 & 0.2\end{array}$

KF-5, Kendall Fort, Barbados

(different subsamples, wall parts)

This Study

Potter et al. (2004)

AC-1, ANU coral powder

This study

Hoffmann et al. (2007a,b)

(integration of 6 separate

measurements)
149.90 .5

$150.4 \quad 1.3$

150.61 .7

$152.2 \quad 2.0$

$152.2 \quad 0.9$

${ }^{a}$ A,B,C,D and E specify separate fragments from the same coral and (1) and (2) denote duplicate, but individually spiked, measurements on the same sample solution. Italicized rows represent samples that are characterised by anomalously low $\left[{ }^{230} \mathrm{Th} /{ }^{238} \mathrm{U}\right]_{\text {act }}$.

b All samples correspond to either drilled dense wall fragments (WP) separated from the bulk sample using a diamond drill, or bulk (bulk) fragments.

${ }^{c}$ Labeled according to species Faviidae (F), Porites (P), Montastria (M) and Acropora (A) corals.

${ }^{\mathrm{d}}$ XRD measurements giving aragonite content in percent (detection limit $1 \%$ ).

e Sample elevations are reported in meters (m) above present mean sea-level (MSL). Estimates of the uncertainties are $\sim 1 \mathrm{~m}$.

f ${ }^{232} \mathrm{Th}$ concentrations in ppb from the MC-ICPMS measurements. Errors are on the order of $20 \%$ (dominated by laboratory ${ }^{232} \mathrm{Th}$ blanks).

${ }^{\mathrm{g}}$ Uranium concentrations are obtained from measured ${ }^{233} \mathrm{U} /{ }^{238} \mathrm{U}$. Errors $( \pm 2 \sigma)$ are estimated as either $0.5 \%$ or $0.25 \%$ with weighing errors contributing as the major source.

${ }^{\mathrm{h}}$ The activity ratios for ${ }^{234} \mathrm{U} /{ }^{238} \mathrm{U}$ (reformulated into $\delta$-notation, whereby $\left.\delta^{234} \mathrm{U}=\left(\left({ }^{234} \mathrm{U} /{ }^{238} \mathrm{U}_{\text {sample }}\right) /\left({ }^{234} \mathrm{U} /{ }^{238} \mathrm{U}_{\text {sec.eq. }}\right)-1\right) \times 10^{3}\right)$ and ${ }^{230} \mathrm{Th} /{ }^{238} \mathrm{U}\left(\left[{ }^{230} \mathrm{Th} /{ }^{238} \mathrm{U}\right]\right.$ act $)$ are calculated by normalization against the "secular equilibrium" standard HU-1, that has been measured in a similar fashion as the corals (Ludwig et al., 1992). The ${ }^{238} \mathrm{U},{ }^{234} \mathrm{U}$ and ${ }^{230} \mathrm{Th}$ half-lives determined by Jaffey et al. (1971) and Cheng et al. (2000) were adopted, assuming HU-1 is in secular equilibrium with respect to ${ }^{230} \mathrm{Th},{ }^{234} \mathrm{U}$ and ${ }^{238} \mathrm{U}$ (Andersen et al., 2008). Variation in ${ }^{238} \mathrm{U} /{ }^{235} \mathrm{U}$ between samples and standards has been incorporated into all calculations; normalization against the true ${ }^{238} \mathrm{U} /{ }^{235} \mathrm{U}$ is used for the instrumental mass bias correction in all ${ }^{234} \mathrm{U} /{ }^{238} \mathrm{U}$ and ${ }^{230} \mathrm{Th} /{ }^{238} \mathrm{U}$ measurements. Either the internal measurement uncertainty (2бm) or the

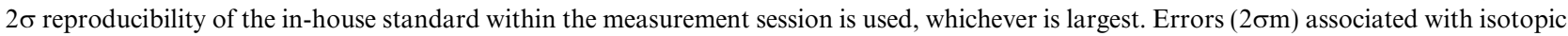
measurements of HU-1 are also incorporated into the uncertainties quoted for the unknowns. Decay constant uncertainties are not incorporated, in order to directly compare with other $\mathrm{U}$-series ages dominated by measurement errors.

${ }^{\mathrm{i}} \mathrm{U}$-series ages are calculated iteratively using: $1-\left[\frac{[230 \mathrm{Th}}{238 \mathrm{U}}\right]$ act $=e^{-\lambda_{230} \mathscr{F}}\left(\frac{\delta^{234} \mathrm{U}(0)}{1000}\right)\left(\frac{\lambda_{230}}{\lambda_{2320}-\lambda_{234}}\right)\left(1-e^{\left(\lambda_{234}-\lambda_{230}\right)} T\right)$ where $T$ is the age in years and $\lambda_{230}$, $\lambda_{234}$, and $\lambda_{238}$ are the decay constants for ${ }^{230} \mathrm{Th},{ }^{234} \mathrm{U}$ and ${ }^{238} \mathrm{U}$, respectively. $\lambda_{238}=1.551 \times 10^{-10} \mathrm{y}^{-1} ; \lambda_{234}=2.826 \times 10^{-6} \mathrm{y}^{-1}$; $\lambda_{230}=9.158 \times 10^{-6} \mathrm{y}^{-1}$. The errors given reflect the propagated analytical errors $(2 \sigma)$ both without decay constant errors and with decay constant errors (in brackets).

${ }^{j}$ The initial $U$ isotopic composition of the sample is given by $\delta^{234} U_{i}=\delta^{234} U e^{\lambda_{234}^{T}}$.

${ }^{\mathrm{k}}$ Open-system U-series model ages are calculated using the Thompson et al. (2003) (TSG\&S) model. The model ages are calculated using the present day seawater $\delta^{234} \mathrm{U}$ of $147 \%$ and half-lives adopted from Cheng et al. (2000). The error includes the contributions from the correction parameters and the analytical contributions from $\delta 234 \mathrm{U}$ and $\left[{ }^{230} \mathrm{Th} /{ }^{238} \mathrm{U}\right]$ act.

(Fig. 5). In this case, the unreliability of NB-D-3 is clearly evident through its unrealistically high value for $\delta^{234} U_{i}$ $(418 \pm 16 \%$ ) and anomalously old conventional U-series age (618 $\pm 14 \mathrm{ka})$ and can be rejected accordingly. Further, U-series observations for Porites and Faviidae corals from
East Beach Unit F (NEB samples) are markedly different. Specifically, the Faviidae corals from this unit appear to be of MIS 9 origin and display the usual correlated shift in $\left[{ }^{230} \mathrm{Th} /{ }^{238} \mathrm{U}\right]_{\text {act }}-\delta^{234} \mathrm{U}$ towards elevated values as a result of diagenesis. In contrast, Porites corals from the same unit 

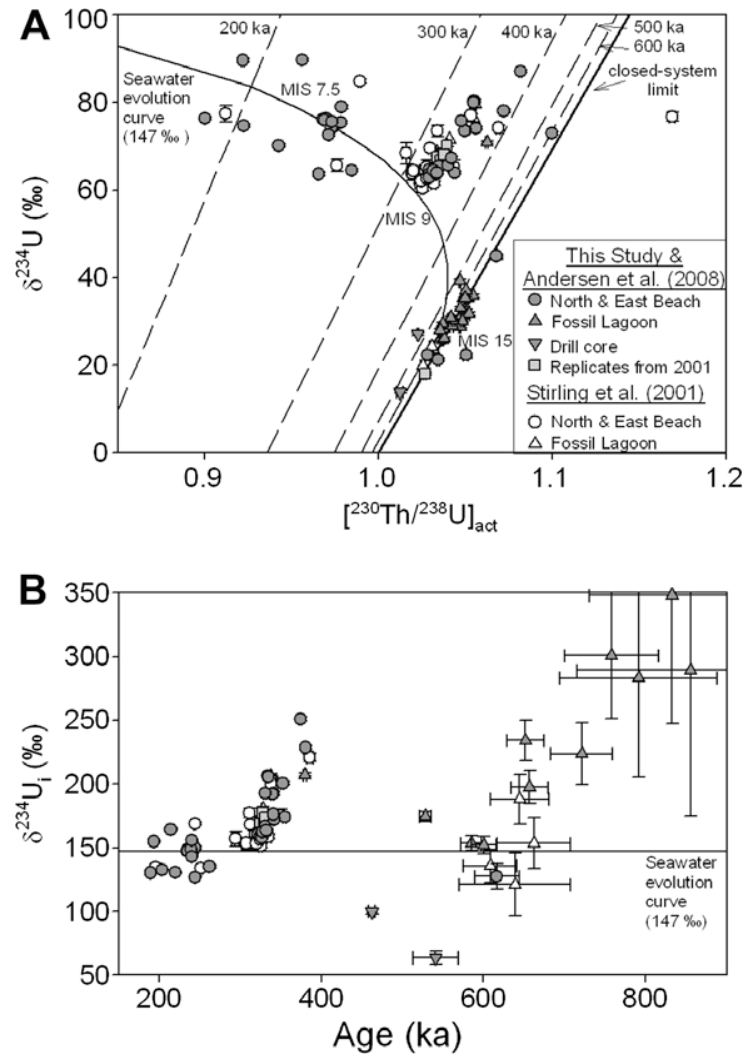

Fig. 3. Compilation of U-series observations for fossil coral reefs on Henderson Island displayed as (A) $\left[{ }^{230} \mathrm{Th} /{ }^{238} \mathrm{U}\right]$ act versus $\delta^{234} \mathrm{U}$ and (B) Age versus the initial, age-corrected $\delta^{234} U$ given by $\delta^{234} U_{\mathrm{i}}$. White symbols represent observations reported in Stirling et al. (2001) and grey symbols denote results from this study and Andersen et al. (2008). All activity ratios have been calculated (or re-calculated) using the half-lives reported in Cheng et al. (2000). The data cluster into three main age groups correlated with MIS 15 (and possibly older interglacial periods), MIS 9 and MIS 7.5. Isochrons for 200$600 \mathrm{ka}$ are shown at $100 \mathrm{ka}$ intervals for reference (sub-vertical dashed lines). The seawater evolution curve sub-horizontal curve in (A) and horizontal line in (B), assuming a $\delta^{234} \mathrm{U}_{\mathrm{i}}$ of $147 \%$, is shown for reference. Pristine corals are generally assumed to plot close to the seawater evolution curve. All three sample suites show varying degrees of U-series open-system behaviour, primarily characterized by a broadly linear and coupled relationship between $\left[{ }^{230} \mathrm{Th} /{ }^{238} \mathrm{U}\right]_{\mathrm{act}}$ and $\delta^{234} \mathrm{U}$ towards elevated values. Secondary open-system shifts, characterized by both an enrichment and depletion in $\left[{ }^{230} \mathrm{Th} /{ }^{238} \mathrm{U}\right]_{\text {act }}$, while $\delta{ }^{234} \mathrm{U}$ remains largely invariant, are also evident in these data. The error bars are $2 \sigma$.

show large, uncorrelated permil- to percent-level variability in $\delta^{234} \mathrm{U}$ and $\left[{ }^{230} \mathrm{Th} /{ }^{238} \mathrm{U}\right]_{\mathrm{act}}$, and a clear deviation in $\left[{ }^{230} \mathrm{Th} /{ }^{238} \mathrm{U}\right]_{\text {act }}$ towards anomalously low values, even for sub-samples from the same coral (e.g. NEB-1, Fig. 5). Inconsistent results between sub-samples means that these Porites samples can be rejected from further discussion.

\subsubsection{Faviidae coral species}

In addition to the abovementioned differences in U-series isotopic composition between Faviidae and Porites corals, marked differences in the U-series isotopic composition are also observed between 'bulk' Faviidae sub-samples and 'wall' Faviidae sub-samples. Most notably, shifts in the
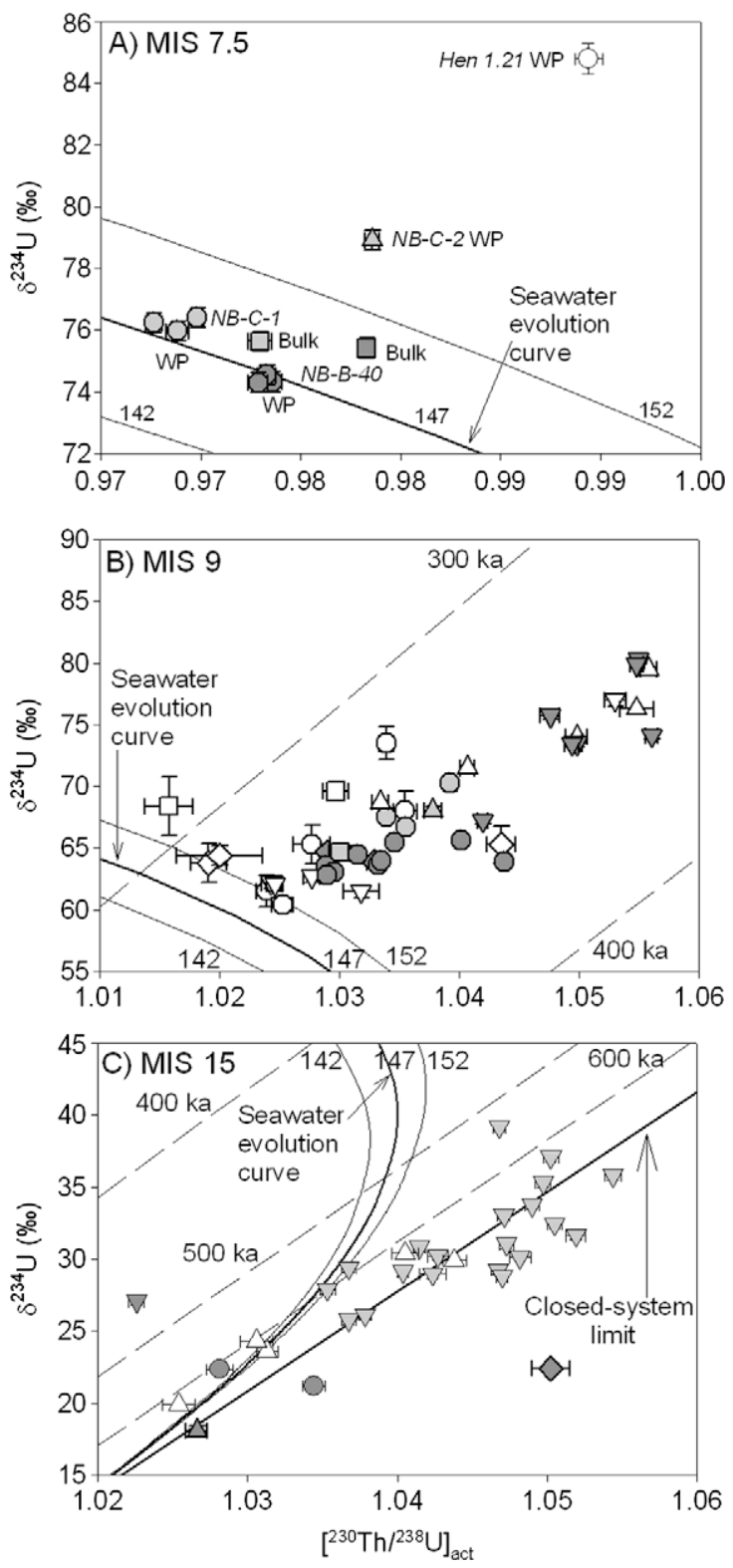

Fig. 4. Compilation of U-series observations for fossil coral reefs on Henderson Island shown as $\left[{ }^{230} \mathrm{Th} /{ }^{238} \mathrm{U}\right]$ act versus $\delta^{234} \mathrm{U}$ focussed on MIS 7.5 (A), MIS 9 (B), and MIS 15 (C). White symbols represent observations reported in Stirling et al. (2001), dark grey symbols denote results from this study, and light grey symbols represent results from Andersen et al. (2008) and Ayling et al. (2006). Isochrons and three different seawater evolution curves $\left(\delta^{234} \mathrm{U}_{\mathrm{i}}=142 \%, 147 \%\right.$ and $152 \%$ ) are shown for reference. Each of the recorded interglacial periods appear to have experienced similar open-system shifts of the U-series isotopes represented by a broadly linear correlation between $\left[{ }^{230} \mathrm{Th} /{ }^{238} \mathrm{U}\right]_{\text {act }}$ and $\delta^{234} \mathrm{U}$ towards elevated values, which plot as an array away from the seawater evolution curves (see the main text for further discussion). The error bars are $2 \sigma$.

U-series isotopic composition towards elevated values are observed in the bulk sub-samples. In the present study, the bulk sample of NB-B-40 (sub-sample D) from North Beach Unit B shows a relative enrichment in $\left[{ }^{230} \mathrm{Th} /{ }^{238} \mathrm{U}\right]_{\text {act }}$ with respect to U-series measurements for the separated 


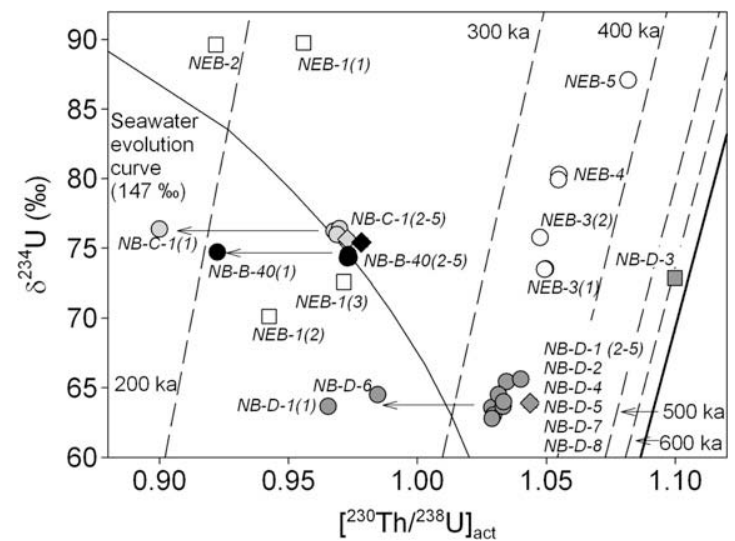

Fig. 5. Compilation of U-series observations for fossil coral reefs on Henderson Island displayed as $\left[{ }^{230} \mathrm{Th} /{ }^{238} \mathrm{U}\right]$ act versus $\delta^{234} \mathrm{U}$. Only corals analysed in replicate, on the basis of multiple measurements of sub-samples, and/or from clearly defined reef units, that are likely to be of the same origin and age, are plotted. Each colour represents a different reef unit as follows: NB-B (black), NB-D (dark grey), NB-C (light grey), NEB (white). Squares represent Porites corals, circles denote wall fragments of Faviidae corals, and diamonds represent bulk samples of Faviidae corals. Sub-sample numbers are given in brackets. Isochrons and the seawater evolution curve $\left(\delta^{234} U_{i}=147 \%\right)$ are shown for reference. All samples show varying degrees of U-series opensystem behaviour, primarily characterized by a broadly linear and coupled relationship between $\left[{ }^{230} \mathrm{Th} /{ }^{238} \mathrm{U}\right]_{\text {act }}$ and $\delta^{234} \mathrm{U}$ towards elevated values. Secondary open-system shifts, characterized by both an enrichment (particularly bulk Faviidae samples) and depletion in $\left[{ }^{230} \mathrm{Th} /{ }^{238} \mathrm{U}\right]_{\text {act }}$, are also evident in these data (see the main text for further discussion). The error bars are $2 \sigma$.

wall fractions of the same coral. Therefore, the bulk subsample of NB-B-40 yields a conventional U-series age of $243.6 \pm 0.5 \mathrm{ka}$ that is $\sim 4 \mathrm{ka}$ older and a $\delta^{234} \mathrm{U}_{\mathrm{i}}$ of $150.1 \pm 0.7 \%$ that is $\sim 3 \%$ o higher, than U-series observations for well-preserved wall fragments of NB-B-40 (Fig. 5). Similarly, the bulk sample of NB-C-1 from North Beach Unit $\mathrm{C}$ has an elevated $\left.{ }^{230} \mathrm{Th} /{ }^{238} \mathrm{U}\right]$ act, relative to wall fragments of the same coral. This translates to a conventional $\mathrm{U}$-series age of $238.7 \pm 0.6 \mathrm{ka}$ for the bulk subsample that is again $\sim 4 \mathrm{ka}$ older than the corresponding U-series ages for three wall fragments of the same coral (Fig. 5). An anomalously high $\left[{ }^{230} \mathrm{Th} /{ }^{238} \mathrm{U}\right]$ act is also observed for the bulk sub-sample of NB-D-1 from North Beach Unit D, which is characterized by an elevated U-series age of $354.7 \pm 1.6 \mathrm{ka}$ (and an elevated $\delta^{234} \mathrm{U}_{\mathrm{i}}$ of $174.1 \pm 1.2 \%$ o,$\sim 30 \mathrm{ka}$ older than the U-series ages for better preserved wall fragments of the same coral (Fig. 5).

Aside from marked differences in the U-series isotopic composition between Porites and Faviidae corals, as well as between bulk and wall fragments of the same Faviidae coral, measurements of multiple wall fragments of the same Faviidae coral also show pronounced U-Th heterogeneity in some samples. For example, of the four replicate measurements for wall fragments from corals NB-B-40 and NB-C-1, in each case, one sub-sample (NB-B-40A and NB-C-1A) displays an anomalously low $\left[{ }^{230} \mathrm{Th} /{ }^{238} \mathrm{U}\right]_{\text {act }}$ (but comparable $\delta^{234} U$ values) with respect to the composition of the three other wall fragments. This translates to anomalously low conventional U-series ages of $203.1 \pm$ 0.3 and $189.1 \pm 0.3 \mathrm{ka}$, as well as low $\delta^{234} \mathrm{U}_{\mathrm{i}}$ values of $132.6 \pm 0.6 \%$ and $130.3 \pm 0.6 \%$ o for NB-C-1A and NB-B-40A, respectively (Fig. 5). In contrast, reproducible U-series ages centered about $\sim 235$ and $\sim 240 \mathrm{ka}$, and $\delta^{234} \mathrm{U}_{\mathrm{i}}$ values of $\sim 148 \%$ and $\sim 147 \%$, are obtained for the remaining three wall fragments of NB-C-1 and NB-B40A, respectively (Fig. 5). For both samples, the U-series age determinations for the 'anomolous' wall pieces are shifted by $30-40$ ka towards younger values compared with the ages derived for the 'well preserved' wall fragments. Similarly, an anomalously low $\left[{ }^{230} \mathrm{Th} /{ }^{238} \mathrm{U}\right]_{\text {act }}$ (but 'normal' $\delta^{234} \mathrm{U}$ ) is obtained for one (sub-sample A) of four wall fragments of NB-D-1 from North Beach Unit D, resulting in a U-series age of $244.0 \pm 0.5 \mathrm{ka}$ that is $>80 \mathrm{ka}$ younger, and a $\delta^{234} \mathrm{U}_{\mathrm{i}}$ of $126.9 \pm 0.7 \%$ that is $\sim 30 \%$ lower than comparable measurements for the three better preserved wall fractions of the same coral. It is also likely that the $\left[{ }^{230} \mathrm{Th} /{ }^{238} \mathrm{U}\right]$ act value of the NB-D-6 wall fragment has been shifted towards anomalously low values on the basis of its low $\delta^{234} \mathrm{U}_{\mathrm{i}}$ of $135.2 \pm 0.7 \%$ and young U-series age of $261.9 \pm 0.6 \mathrm{ka}$, when it is considered in the context of the entire dataset for reef Unit D (Fig. 5).

\section{DISCUSSION}

\subsection{U-Th open-system behaviour and possible alteration mechanisms}

It has been proposed that relative enrichments in $\left.{ }^{230} \mathrm{Th} /{ }^{238} \mathrm{U}\right]$ act, such as those observed in bulk sub-samples of NB-B-40, NB-C-1 and NB-D-1, are correlated with calcite alteration (e.g. Eggins et al., 2005). For 'wall' samples, this presumably arises because the well-preserved, denser wall fraction tends to retain some, if not all, of its primary isotopic signature, whereas for 'bulk' samples, the well-preserved wall fraction is sampled together with the porous 'septa' fraction that is prone to remineralisation as well as detrital contamination. In the present study, it is likely that minor calcite replacement (below the 1\% calcite detection limit of the XRD measurements) has occurred in the porous septa fraction of the bulk samples. However, the apparent deviation in $\left.{ }^{230} \mathrm{Th} /{ }^{238} \mathrm{U}\right]$ act towards lower values that occurs in some wall fragments of the Henderson Island samples, without significantly changing the composition of $\delta^{234} \mathrm{U}$, is not typically observed in fossil reef systems. A viable mechanism for creating shifts in $\left[{ }^{230} \mathrm{Th} /{ }^{238} \mathrm{U}\right]_{\text {act }}$ towards lower values is if some parts of the coral have experienced $\mathrm{U}$ addition at a late stage in their post-depositional history. This is exemplified in several studies. For example, a study of MIS 6.5 ( $\sim 175 \mathrm{ka})$ Acropora Palmata corals from Barbados shows subtle but systematic shifts toward lower $\left[{ }^{230} \mathrm{Th} /{ }^{238} \mathrm{U}\right]$ act correlated with higher $\mathrm{U}$ concentrations, without notable shifts in the $\delta^{234} \mathrm{U}$ of the corals (Scholz et al., 2006). The authors attributed this to internal redistribution of U within the coral (Scholz et al., 2006). Also, in a study of alteration processes occurring in deep-sea corals, Robinson et al. (2006) observed a large heterogeneity in $\mathrm{U}$ concentration within a single coral. They also observed uranium enrichment within parts of the coral displaying 
surface areas exposed to bio-erosion that were covered by an organic film, and suggested that this organic layer can be highly enriched in U. Similarly, a fossil coral from the southern Sinai coastal margin adjacent to the Red Sea exhibited black organic surface discoloration prior to physical cleaning, and had very high $U$ concentrations of $\sim 8.5 \mathrm{ppm}$, more than a factor of two larger than better preserved corals located nearby that showed no organic discolouration (Gvirtzman et al., 1992).

An explanation of this type could explain the $\left[{ }^{230} \mathrm{Th} /{ }^{238} \mathrm{U}\right]_{\text {act }}$ shifts observed in some of the analysed Henderson Island corals, all of which appeared unaltered during pre-selection. For instance, the Porites corals from East Beach Unit $F$ that display extensive open-system U-series behaviour and large variability in $\left[{ }^{230} \mathrm{Th} /{ }^{238} \mathrm{U}\right]_{\text {act }}$ and $\delta^{234} \mathrm{U}$ (Fig. 5) appear exceptionally well-preserved and even exhibit pristine annual cycles of $\mathrm{Sr} / \mathrm{Ca}$ and U/Ca (see Ayling et al., 2006); in these samples, the only indicator of diagenetic alteration is minor dissolution along the centers of calcification. Despite the excellent preservation of these samples, it is possible that some parts of the coral have been extensively coated with a secondary U-rich organic film that contained no Th, and was transported to the reef via pore- or ground-water at a later stage of the coral's post-depositional history. Then shifts in both $\left[{ }^{230} \mathrm{Th} /{ }^{238} \mathrm{U}\right]_{\text {act }}$ and $\delta^{234} \mathrm{U}$ towards anomalous values could readily be created in affected areas of the coral. Clearly, the magnitude of the latter would be dependent on the ground-water $\delta^{234} U$ composition. In the context of Henderson Island's fossil corals, a ground-water sample recovered from the base of the North Beach drill-core gave rise to a $\delta^{234} \mathrm{U}$ of $70 \pm 1 \%$ and a measurement of the bulk carbonate matrix from above the drill hole gave a $\delta^{234} U$ of $63 \pm 1 \%$ (unit NB-A). Importantly, these values are very similar to the measured $\delta^{234} U$ compositions reported for the majority of MIS 7 and MIS 9 fossil corals, which have values ranging from $62 \%$ to $80 \%$ o (Tables 2 and 3 ). The measured ground-water composition might reflect direct dissolution of the fossil corals and carbonate matrix, either continuously, or at discrete time intervals over the last $300 \mathrm{ka}$ since the time of formation of Henderson Island's fringing reefs. Thus, any percent-level addition of $U$ from this source, or from the internal redistribution of $U$ within the fossil coral skeleton, would not significantly alter $\delta^{234} \mathrm{U}$ but could drastically change $\left[{ }^{230} \mathrm{Th} /{ }^{238} \mathrm{U}\right]_{\text {act }}$. Moreover, it is reasonable to expect that corals situated in a zone subjected to a large percolation of phreatic waters would be more prone to this $\mathrm{U}$ addition effect than corals lying outside of this zone. This is supported by the observation that deviations towards lower $\left[{ }^{230} \mathrm{Th} /{ }^{238} \mathrm{U}\right]_{\text {act }}$ are scarcely observed in samples collected from the upper fossil lagoon. In contrast, those collected from the margins of Henderson Island near present sea-level, and especially the two fossil corals recovered from the drill-core at -9 and $-17 \mathrm{~m}$ with respect to present sea-level, appear to show depleted $\left[{ }^{230} \mathrm{Th} /{ }^{238} \mathrm{U}\right]_{\text {act }}$ compositions and low $\delta^{234} \mathrm{U}_{\mathrm{i}}(100.1 \pm 0.7 \%$ and $63.8 \pm 5.2 \%$, respectively), presumably due to increased phreatic water percolation in these sub-surface zones within the reef (Fig. 3). It is also important to note that, in contrast to the well-preserved sub-aerial samples, the two drill core corals show clear signs of secondary aragonite formation and a brownish discolour- ation, the latter of which indicates the presence of organic material.

Clearly, further studies are warranted to gain a better understanding of the open-system process/es responsible for shifting $\left[{ }^{230} \mathrm{Th} /{ }^{238} \mathrm{U}\right]_{\text {act }}$ and $\delta^{234} \mathrm{U}_{\mathrm{i}}$ towards anomalously low values without changing the measured $\delta^{234} \mathrm{U}$. Importantly, this may be a relatively common open-system process in coral reefs, exemplified in the similar observations reported for the MIS 6.5 Barbados corals (Scholz et al., 2006). In this respect, better constraints on possible variations in $\mathrm{U}$ concentration within the internal structure of the fossil coral, in combination with the U-series isotopic measurements, may provide important information. In this study, fossil corals affected by a contamination process of this type can easily be identified and screened out on the basis of their anomalously low $\delta^{234} \mathrm{U}_{\mathrm{i}}$, particularly when these values are considered in the context of other stratigraphically similar corals, and most critically, by comparison with replicate measurements for other sub-samples from the same coral.

The observed open-system behaviour is important for the application of open-system model ages. Two open-system models have been devised for fossil corals that are based explicitly on the addition (or loss) of $\alpha$-recoil nuclides to (or from) the paleo-reef system. In the models of Thompson et al (2003), (TSG\&S) and Villemant and Feuillet (2003) (V\&F) differential equations taking into account (1) radioactive decay of the U-series nuclides, and (2) ${ }^{234} \mathrm{Th}$ and ${ }^{230} \mathrm{Th}$ addition (or loss) by $\alpha$-recoil redistribution describe the open-system addition trends as a theoretical forward model. The equations are inverted to allow the derivation of an open-system U-series age that is corrected for isotope addition (or loss) constrained by the intersection of the addition line with the closed-system seawater evolution curve. The TSG\&S model allows open-system age constraints to be derived for individual samples, whereas the V\&F model calculates one "average" open-system U-series model age for the entire reef unit. Importantly, both models assume that $\alpha$-recoil mobilisation is the only U-Th alteration process operating within the reef unit. The primarily difference between these two models is with regard to the treatment of (1) the $\alpha$-recoil redistribution factors for ${ }^{234} \mathrm{Th}$ and ${ }^{230} \mathrm{Th}$, and $(2)$ the inversion procedure used to calculate the open-system ages. In a third suite of open-system models, referred to as linear regression or "open-system isochron" models (Potter et al., 2004; Scholz et al., 2004), the model trends are derived empirically, constrained by the observed relationship between ${ }^{230} \mathrm{Th}$ and ${ }^{234} \mathrm{U}$, as opposed to the chemical and physical processes of $\alpha$-recoil and radioactive decay. A linear regression is applied to the entire coral dataset in ${ }^{230} \mathrm{Th} /{ }^{238} \mathrm{U}-{ }^{234} \mathrm{U} /{ }^{238} \mathrm{U}$ space, and an average open-system $\mathrm{U}$-series model age is derived for the reef unit based upon the point at which the regression line intercepts the seawater evolution curve. In the context of the Henderson Island samples, the open-system models based on $\alpha$-recoil mechanisms will clearly yield unreliable open-system U-series ages when they are applied to samples that have been affected by the open-system trends whereby $\left[{ }^{230} \mathrm{Th} /{ }^{238} \mathrm{U}\right]_{\text {act }}$ deviates towards lower or higher values while $\delta^{234} \mathrm{U}$ remains invariant. 
Table 3

U-Th isotope ratios and U-series ages for Henderson Island fossil corals reported in Stirling et al. (2001).

\begin{tabular}{|c|c|c|c|c|c|c|c|c|c|c|c|c|c|}
\hline Sample $^{\mathrm{a}}$ & $-^{c}$ & $\mathrm{MSL}^{\mathrm{e}}$ & $\begin{array}{l}{ }^{232} \mathrm{Th}^{\mathrm{f}} \\
(\mathrm{ppb})\end{array}$ & \multicolumn{2}{|c|}{$\delta^{234} \mathrm{U}^{\mathrm{h}}$} & \multicolumn{2}{|c|}{$\left[{ }^{230} \mathrm{Th} /{ }^{238} \mathrm{U}\right]_{\mathrm{act}}{ }^{\mathrm{h}}$} & \multicolumn{2}{|c|}{ Age $(\mathrm{ka})^{\mathrm{i}}$} & $\begin{array}{l}\delta^{234} U_{i}^{j} \\
(\% o)\end{array}$ & $\delta^{234} U_{i}^{j}$ & \multicolumn{2}{|c|}{$\mathrm{O}-\mathrm{S}$ age $(\mathrm{ka})^{\mathrm{k}}$} \\
\hline \multicolumn{14}{|c|}{ NORTH BEACH } \\
\hline Hen 1.6 & A & 7 & 0.01 & 68.0 & 1.6 & 1.0355 & 0.0010 & 326.3 & $4.2(4.2)$ & 171.0 & 4.5 & 309.4 & 7.6 \\
\hline Hen 1.10 & $\mathrm{M}$ & 2 & 0.01 & 65.3 & 1.6 & 1.0277 & 0.0015 & 318.4 & $4.4(4.4)$ & 160.6 & 4.4 & 308.9 & 6.7 \\
\hline Hen 1.21 & $\mathrm{M}$ & 20 & 0.07 & 84.8 & 0.5 & 0.9894 & 0.0007 & 244.0 & $0.8(0.8)$ & 169.0 & 1.1 & 232.0 & 4.1 \\
\hline Hen 1.22 & PA & 20 & 0.16 & 65.7 & 1.4 & 0.9760 & 0.0009 & 251.7 & $1.8(1.8)$ & 133.8 & 2.9 & 259.4 & 5.1 \\
\hline Hen 1.23 & $\mathrm{M}$ & 20 & 0.01 & 73.5 & 1.3 & 1.0339 & 0.0006 & 311.6 & $2.8(2.8)$ & 177.3 & 3.4 & 291.5 & 7.3 \\
\hline Hen $1.26 \mathrm{a}$ & M & 26 & 0.01 & 61.5 & 1.3 & 1.0239 & 0.0008 & 320.1 & $3.2(3.3)$ & 152.0 & 3.5 & 316.6 & 6.2 \\
\hline Hen $1.26 \mathrm{~b}$ & $\mathrm{M}$ & 26 & $<0.00$ & 60.4 & 0.6 & 1.0253 & 0.0009 & 325.1 & $2.2(2.2)$ & 151.4 & 1.8 & 322.0 & 6.4 \\
\hline Hen 5.6(1) & $\mathrm{L}$ & 24 & 0.02 & 62.2 & 0.5 & 1.0243 & 0.0008 & 319.2 & $1.8(2.0)$ & 153.3 & 1.5 & 314.8 & 1.9 \\
\hline Hen $5.6(2)$ & $\mathrm{L}$ & 24 & 0.03 & 62.1 & 0.6 & 1.0246 & 0.0007 & 320.0 & $1.8(2.0)$ & 153.4 & 1.6 & 315.4 & 1.9 \\
\hline Hen 5.7 & $\mathrm{~L}$ & 29 & 0.01 & 62.7 & 0.5 & 1.0277 & 0.0007 & 324.2 & $1.7(1.9)$ & 156.7 & 1.5 & 317.2 & 2.3 \\
\hline \multicolumn{14}{|c|}{ EAST BEACH } \\
\hline Hen 2.1 & $\mathrm{P}$ & 5 & 0.51 & 76.7 & 1.0 & 1.1690 & 0.0015 & - & & - & & - & \\
\hline Hen $2.2 \mathrm{a}$ & $\mathrm{P}$ & 8 & 0.04 & 63.8 & 1.6 & 1.0191 & 0.0015 & 307.2 & $3.9(4.0)$ & 152.0 & 4.2 & 303.8 & 2.3 \\
\hline Hen $2.2 \mathrm{~d}$ & $\mathrm{P}$ & 8 & 0.13 & 64.4 & 0.8 & 1.0200 & 0.0036 & 307.5 & $5.9(6.0)$ & 153.6 & 3.2 & 303.0 & 4.5 \\
\hline Hen 2.6 & $\mathrm{P}$ & 19 & 0.17 & 65.3 & 1.5 & 1.0435 & 0.0012 & 349.8 & $5.2(5.3)$ & 175.5 & 4.8 & 328.5 & 5.4 \\
\hline Hen $2.7 \mathrm{a}$ & $\mathrm{P}$ & 18 & 0.21 & 68.4 & 2.4 & 1.0158 & 0.0020 & 293.9 & $4.9(5.0)$ & 157.0 & 5.9 & 287.5 & 2.7 \\
\hline Hen $2.7 \mathrm{c}$ & $\mathrm{P}$ & 18 & 0.89 & 69.6 & 0.4 & 1.0297 & 0.0011 & 312.7 & $2.0(2.1)$ & 168.4 & 1.3 & 298.2 & 3.5 \\
\hline Hen 3.3 & $\mathrm{P}$ & 5 & 0.05 & 74.2 & 0.5 & 1.0688 & 0.0012 & 385.9 & $4.2(4.2)$ & 220.8 & 3.0 & 333.7 & 4.4 \\
\hline Hen 3.11 & $\mathrm{P}$ & 21 & 0.07 & 77.0 & 0.5 & 1.0530 & 0.0009 & 338.0 & $2.2(2.2)$ & 200.1 & 1.8 & 301.2 & 8.0 \\
\hline Hen 4.1 & M & 7 & 0.07 & 61.5 & 0.5 & 1.0318 & 0.0015 & 335.1 & $3.3(3.4)$ & 158.5 & 2.0 & 326.6 & 3.4 \\
\hline Hen 4.12 & $\mathrm{M}$ & 16 & 0.01 & 77.4 & 1.9 & 0.9117 & 0.0010 & 195.0 & $1.3(1.4)$ & 134.3 & 3.3 & 201.1 & 2.1 \\
\hline \multicolumn{14}{|c|}{ FOSSIL LAGOON } \\
\hline FH 152 & $\mathrm{~F}$ & 24 & 0.12 & 71.5 & 0.5 & 1.0407 & 0.0006 & 327.7 & $1.6(1.8)$ & 180.5 & 1.5 & 304.4 & 5.0 \\
\hline FH 172 & $\mathrm{P}$ & 24 & 0.96 & 76.3 & 0.6 & 1.0548 & 0.0014 & 343.5 & $3.4(3.5)$ & 201.4 & 2.5 & 305.3 & 8.7 \\
\hline FH 350 & $\mathrm{~F}$ & 24 & $<0.00$ & 68.7 & 0.5 & 1.0334 & 0.0007 & 320.9 & $1.7(1.9)$ & 170.1 & 1.5 & 304.9 & 3.6 \\
\hline FH 352 & $\mathrm{~F}$ & 24 & 0.05 & 74.0 & 0.6 & 1.0498 & 0.0009 & 339.3 & $2.4(2.6)$ & 193.0 & 2.1 & 306.9 & 7.1 \\
\hline FH 416 & $\mathrm{~F}$ & 24 & 0.06 & 79.5 & 0.6 & 1.0558 & 0.0007 & 337.2 & $2.1(2.2)$ & 206.2 & 2.0 & 296.7 & 8.6 \\
\hline FH 310 & $\mathrm{~F}$ & 24 & 0.02 & 30.4 & 0.4 & 1.0405 & 0.0009 & 645 & $36(36)$ & 188 & 19 & 588 & 11 \\
\hline FH 328a & $\mathrm{F}$ & 24 & - & 19.9 & 1.2 & 1.0254 & 0.0011 & 639 & $69(69)$ & 121 & 25 & 683 & 22 \\
\hline FH 328b & $\mathrm{F}$ & 24 & 0.01 & 23.6 & 0.6 & 1.0313 & 0.0007 & 662 & $45(45)$ & 153 & 20 & 652 & 13 \\
\hline FH $328 \mathrm{c}$ & $\mathrm{F}$ & 24 & 0.02 & 24.3 & 0.5 & 1.0306 & 0.0011 & 609 & $33(33)$ & 136 & 13 & 626 & 15 \\
\hline FH 407 & $\mathrm{~F}$ & 24 & 0.04 & 29.9 & 0.5 & 1.0438 & 0.0008 & - & & - & & - & \\
\hline
\end{tabular}

Data from Stirling et al. (2001) have been re-calculated using the half-lives determined by Cheng and coworkers (2000). This leads to slightly higher $\delta^{234} \mathrm{U}_{\mathrm{i}}$ with respect to the modern marine value compared with the results reported in Stirling et al. (2001), which used older half life values. Sample names are taken from Stirling et al. (2001), $\mathrm{A}=$ Acropora, $\mathrm{M}=$ Montastria, $\mathrm{F}=$ Faviidae, $\mathrm{P}=$ Porites, $\mathrm{PA}=$ Paconia, $\mathrm{L}=$ Letonia. See footnotes to Table 2 for additional descriptions.

\subsection{Marine Isotope Stage 7.5 at Henderson Island}

\subsection{1. $U$-series ages estimates and the marine $\delta^{234} U$ during MIS 7.5}

Reef development on Henderson Island during MIS 7.5 appears to have occurred as minor patch reef structures. This is evidenced by the reef morphology and by the limited number of accessible samples, compared with the more abundant and prolific reef growth that occurred during MIS 9 (Fig. 2). Conventional U-series measurements for fossil corals NB-B40, NB-C-1 and NB-C-2 are suggestive of a MIS 7.5 origin (230-245 ka) (Fig. 6). A U-series age of $240.4 \pm 0.4 \mathrm{ka}$ is obtained for NB-C-2, however, its $\delta^{234} \mathrm{U}_{\mathrm{i}}(155.7 \pm 0.6 \%$ o $)$ is slightly elevated compared with the value for NB-C-1 from the same reef unit, which may be indicative of minor diagenetic alteration in this sample. The three well-preserved wall sub-samples of NB-B-40 (excluding the fourth sub-sample with a lower $\left[{ }^{230} \mathrm{Th} /{ }^{238} \mathrm{U}\right]_{\text {act }}$ as discussed in Section 4.1) yield identical U-series ages of $240.6 \pm 0.5,240.1 \pm 0.5$ and
$240.0 \pm 0.5 \mathrm{ka}$, and identical $\delta^{234} \mathrm{U}_{\mathrm{i}}$ of $146.7 \pm 0.7 \%$, $147.0 \pm 0.7 \%$ and $146.3 \pm 0.7 \%$, respectively (Fig. 6). In addition, the three well-preserved wall fragments of NB-C1 (again excluding the fourth sub-sample with a lower $\left.\left[{ }^{230} \mathrm{Th} /{ }^{238} \mathrm{U}\right]_{\text {act }}\right)$ give similar $\mathrm{U}$-series ages of $233.8 \pm 0.4$, $235.4 \pm 0.4$ and $235.0 \pm 0.6 \mathrm{ka}$, with minor age differences arising due to slight heterogeneity in $\left[{ }^{230} \mathrm{Th} /{ }^{238} \mathrm{U}\right]_{\text {act }}$ between sub-samples (Fig. 6). These sub-samples have identical $\delta^{234} U_{i}$ of $147.6 \pm 0.6 \%, 148.6 \pm 0.6 \%$ and $147.6 \pm 0.7 \%$, respectively. Expanding the error limits to take into consideration the full variability displayed by the sub-samples yields mean U-series ages of $240.3 \pm 0.8 \mathrm{ka}$ for NB-B-40 and $234.7 \pm$ $1.3 \mathrm{ka}$ for NB-C-1. These samples also have mean $\delta^{234} \mathrm{U}_{\mathrm{i}}$ of $146.7 \pm 1.0 \%$ and $147.9 \pm 1.2 \%$, respectively, overlapping both each other $\left(147 \pm 1 \%\right.$ ) and the modern marine $\delta^{234} \mathrm{U}$ value $(147 \%)$.

The above-mentioned U-series observations are suggestive of either (a) a prolonged period of interglacial or interstadial conditions during MIS 7.5, allowing continuous 
coral growth over at least $\sim 5 \mathrm{ka}$ from $\sim 240$ to $\sim 235 \mathrm{ka}$, (b) two distinct climate events occurring at $\sim 240$ and $\sim 235 \mathrm{ka}$ separated by a hiatus, or (c) a combination of these two end-member scenarios. Clearly, further efforts are required to verify these findings, however, they are supported by two additional observations. First, when plotted in $\left[{ }^{230} \mathrm{Th} /{ }^{238} \mathrm{U}\right]_{\mathrm{act}}-\delta^{234} \mathrm{U}$ space, U-series isotopic data for fossil corals NB-C-2 (sampled adjacent to NB-C-1) and Hen 1-21 (sampled during the 1990-1991 Pitcairn Scientific Expedition and reported in Stirling et al. (2001)) define a linear trend anchored by the U-series isotopic composition of unaltered sub-samples of NB-C-1 (Fig. 4). This may imply that both NB-C-2 and Hen 1-21 had the same isotopic composition as NB-C-1 at the time of formation and are thus of the same age as NB-C-1. The linear relationship defined by all three samples offers the possibility to apply an open-system correction to the data. Application of the TSG\&S open-system U-series model to both NB-C-2 and Hen $1-21$, adopting an initial $\delta^{234} U$ of $147 \%$ (equivalent to the composition of both present day seawater and the assumed unaltered MIS 7.5 samples) for all calculations, yields identical open-system U-series ages of 235.6 \pm 0.9 and $232.0 \pm 4.1 \mathrm{ka}$, respectively. These open-system ages are indistinguishable from the mean conventional U-series age estimate of $234.7 \pm 1.3 \mathrm{ka}$ for the well-preserved subsamples of NB-C-1. It is important to bear in mind that each permil deviation in the true initial $\delta^{234} \mathrm{U}$ composition away from the assumed value of $147 \%$ corresponds to a $\sim 0.5$ ka shift in the TSG\&S open-system model ages away from the true age in MIS 7 corals (Fig. 7). However, the fact that both the open-system ages and the 'reliable' conventional age are in agreement argues strongly for the robustness of both the closed-system and open-system approach for these marginally altered samples (Fig. 6). Second, the $\delta^{234} \mathrm{U}_{\mathrm{i}}$ obtained for 'reliable' sub-samples of NBC-1 dated at $\sim 235 \mathrm{ka}$ are identical to those obtained for 'reliable' sub-samples of NB-B-40 dated at $\sim 240 \mathrm{ka}$, as would be expected if both samples formed in the marine environment under the same $U$ isotopic conditions despite their differing ages. While it cannot be excluded that both corals have experienced the same degree of minor alteration, manifested by the same diagenetic shift in $\delta^{234} U_{i}$, this would seem an unlikely coincidence given their differing measured $\delta^{234} \mathrm{U}$ and $\left[{ }^{230} \mathrm{Th} /{ }^{238} \mathrm{U}\right]_{\text {act }}$ values.

Stirling and Andersen (2009) suggest that the dependence of the $\delta^{234} \mathrm{U}_{\mathrm{i}}$ screening criterion upon the modern marine $\delta^{234} U$ can potentially be overcome for suitably large datasets displaying clearly defined systematic open-system U-series trends. This is especially the case when a significant proportion of the data cluster about a specific $\delta^{234} U_{i}$, which may define the "pristine" signature of the corals and the $\delta^{234} \mathrm{U}$ composition of seawater at the time the reef formed (Stirling and Andersen, 2009). This is the approach followed in the present study. Specifically, reliable U-series observations for MIS 7.5 are based on (a) the overlapping $\delta^{234} \mathrm{U}_{\mathrm{i}}$ of two independent corals (NB-B-40, $146.7 \pm 1.0 \%$ and NB-C-1, $147.9 \pm 1.2 \%$ ) discussed above that are considered to have experienced minimal, if any, diagenetic alteration, combined with (b) the systematic open-system linear trend exhibited by sample NB-C-2. This is opposed
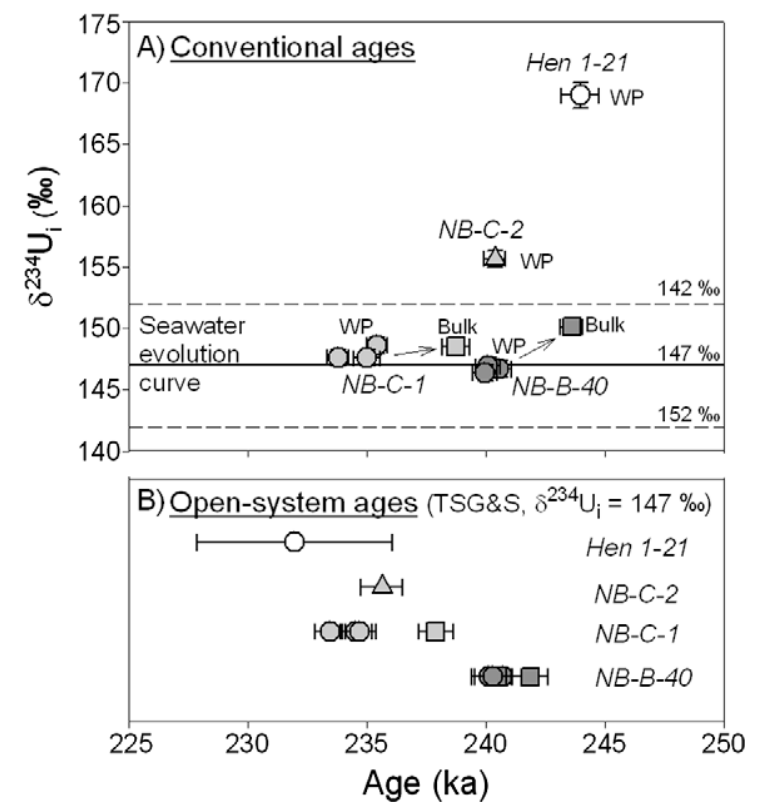

Fig. 6. U-series observations for MIS 7.5 fossil reefs on Henderson Island displayed as (A) $\mathrm{U}$-series age versus initial $\delta^{234} \mathrm{U}_{\mathrm{i}}$ (omitting sub-samples with anomalously low $\left[{ }^{230} \mathrm{Th} /{ }^{238} \mathrm{U}\right] \mathrm{act}$ ) and (B) TSG\&S open-system U-series ages for the same samples. White symbols represent observations reported in Stirling et al. (2001) and grey symbols denote results from this study. In (A) replicate measurements of 'wall' sub-samples (WP; circles and triangles) of NB-C-1 and NB-B-40 show very good internal consistency, yielding Useries ages of $\sim 235$ and $240 \mathrm{ka}$, respectively, although NB-C-1 displays minor heterogeneity in the U-series isotopic composition between sub-samples, most likely due to low-level diagenetic alteration. Both sets of replicate measurements plot on, or very close to, the seawater evolution curve $\left(\delta^{234} U_{i}=147 \%\right)$ which is shown for reference. 'Bulk' samples (squares) of both NB-B-40 and NB-C-1 yield considerably older conventional U-series ages compared with their wall fragment (circles) counterparts due to an enrichment in $\left[{ }^{230} \mathrm{Th} /{ }^{238} \mathrm{U}\right]_{\text {act }}$. Wall fractions of fossil corals NB-C1, NB-C-2 and Hen 1-21 appear to lie along the same linear trend defined by shifts in $\left[{ }^{230} \mathrm{Th} /{ }^{238} \mathrm{U}\right]$ act and $\delta^{234} \mathrm{U}$ towards elevated values away from the seawater evolution curve, which may indicate that they have the same true age. In (B) there is good agreement between the TSG\&S open-system ages for the wall sub-samples of NB-C-1, NB-C-2 and Hen 1-21. Importantly, bulk fractions of both NB-B-40 and NB-C-1 yield open-system ages that are systematically older than those determined for wall sub-samples of the same corals. This is most likely due to second order opensystem shifts with respect to $\left[{ }^{230} \mathrm{Th} /{ }^{238} \mathrm{U}\right]$ act in the bulk sub-samples only that are not taken into account by the open-system model. The error bars are $2 \sigma$.

to screening for reliability using a fixed $\delta^{234} U$ criterion centred about the modern marine value, and it is entirely fortuitous that both NB-C-1 and NB-C-40 have exactly the same $\delta^{234} U_{i}$ as modern seawater. We consider that these observations provide the first independent estimate of the marine $8234 \mathrm{U}$ during MIS 7.5. This is important in the context of the increasing body of data implying that the $\delta^{234} \mathrm{U}$ of seawater may have been lower than present during the last glacial cycle when sea-level was also lower than present (Cutler et al., 2004; Esat and Yokoyama, 2006; Robinson et al., 2004). 


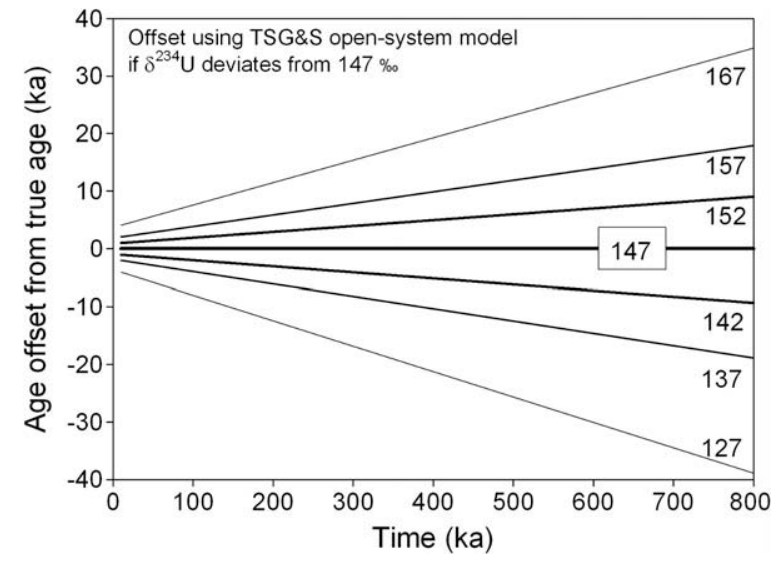

Fig. 7. TSG\&S open-system U-series age (ka) versus offset from the true age if an incorrect value for the marine $\delta^{234} \mathrm{U}$ is propagated through the calculations. The lines represent different scenarios of the marine $\delta^{234} \mathrm{U}$ through time and show an increasing importance with increasing age. If the marine $\delta^{234} U$ has been constant and equal to $147 \%$ through the last $800 \mathrm{ka}$, identical to the present day value, then no offset occurs during the calculation of the opensystem ages. However, if the marine $\delta^{234} U$ was, for example, $152 \%$ at $300 \mathrm{ka}$, but a composition of $147 \%$ is adopted to calculate an open-system age, the TSG\&S model will give an open-system age that is $3.4 \mathrm{ka}$ younger than the true age. The additional uncertainties arising if the marine $\delta^{234} \mathrm{U}$ is unknown at the time the fossil coral formed should be incorporated into the errors associated with the TSG\&S open-system model ages. Similar uncertainties can also be incorporated into the errors associated with conventional Useries ages if a $\delta^{234} \mathrm{U}_{\mathrm{i}}$ criterion for reliability based upon a marine $\delta^{234} \mathrm{U}$ centred about the modern marine value is used to screen 'acceptable' samples.

Clearly, there remains considerable uncertainty in the marine $\delta^{234} U$ composition during the Quaternary. If the marine $\delta^{234} \mathrm{U}$ composition at the time a sample formed cannot be reliably constrained, then it is advisable to assign an additional error to the adopted seawater $\delta^{234} U$ and propagate this uncertainty through the U-series age calculations to circumvent the dependence on the assumption of a constant and uniform marine $\delta^{234} U$ throughout the Quaternary. This approach should be followed in (1) conventional U-series dating when a fixed $\delta^{234} U$ screening criterion centered about the modern marine value of $147 \%$ is used to assess the reliability of samples, and (2) open-system U-series calculations when the marine $\delta^{234} \mathrm{U}$ is a critical input parameter. In both cases, shifts in the TSG\&S open-system ages incurred when the true $\delta^{234} \mathrm{U}$ differs from the assumed value can be used as a first order guide to assign an additional uncertainty to the U-series age (Fig. 7).

\subsubsection{The timing of MIS 7.5}

The relationship between the heights of Henderson Island's fossil coral reefs and eustatic sea-level is uncertain due to (1) a limited knowledge of the uplift history of the island through the non-uniform processes of lithospheric flexure, and (2) continuous glacio-hydro-isostatic adjustment of the ocean, lithosphere and mantle to the changing mass and distribution of ice and melt-water loading. A eustatic sea-level curve for MIS 7.5, based upon the U-series observations for Henderson Island, will thus be derived in a separate study through a combination of glacio-hydro-isostatic and lithospheric flexural modelling.

Our U-series observations do, however, provide important constraints on the timing and duration of MIS 7.5 for the purpose of comparison with other independently-dated climate records (Fig. 8). Regarding the onset of the MIS 7.5 sea-level high-stand, our Henderson Island observations indicate that peak interglacial/interstadial sea-levels had been attained by $240.3 \pm 0.8 \mathrm{ka}$. This is in very good agreement with a revised sea-level curve for Barbados based on the open-system U-series dating (using the TSG\&S model) of altered fossil corals (Thompson and Goldstein, 2005), which suggests that peak sea-level was reached between $243 \pm 4 \mathrm{ka}$ and $239 \pm 6 \mathrm{ka}$. Also, the initiation of MIS 7.5 reef growth on Henderson Island at $240.3 \pm 0.8 \mathrm{ka}$ coincides with, or slightly post-dates, the $\sim 241 \mathrm{ka}$ predicted timing of peak summer solar insolation at latitude $65^{\circ} \mathrm{N}$, and is thus consistent with the Milankovitch theory of climate change (Fig. 8). Our new Henderson Island results are also in good agreement with U-series observations for aragonitic slope sediments from the Bahamas, which suggest that full interglacial conditions were reached at $\sim 237 \mathrm{ka}$ (Henderson et al., 2006; Robinson et al., 2002). The error limits associated with the Bahamian slope sediments are, however, sizeable and exceed $\pm 5 \mathrm{ka}$, which precludes a direct comparison of the two data sets. With regard to sea-level amplitudes, U-series ages acquired for submerged calcitic flowstones in the Bahamas suggest a relative sea-level high-stand of at most $-10 \mathrm{~m}$ with respect to present sea-level between 230 and $233 \mathrm{ka}$ (Li et al., 1989; Lundberg and Ford, 1994), although these interpretations are based upon U-series ages with associated errors exceeding $\pm 10 \mathrm{ka}(2 \sigma)$ and thus the exact timing is not well constrained. Also, a recent study of submerged speleothems at Argentarola, Italy are indicative of a relative sea-level high-stand above $-18 \mathrm{~m}$ with respect to present sealevel initiated after $248.9 \pm 1.9 \mathrm{ka}$ with sea-level falling below $-18 \mathrm{~m}$ by $231.0 \pm 3.0 \mathrm{ka}$ (Dutton et al., 2009). In particular, the youngest $\mathrm{U}$-series age for the relative sea-level high-stand at Argentarola $(231.0 \pm 3.0 \mathrm{ka})$ agrees well with the youngest coral age for Henderson Island $(234.7 \pm 1.3 \mathrm{ka})$. The Argentorola observation is assumed to constrain the regression of the MIS 7.5 sea-level high-stand, whereas the Henderson Island result is believed to constrain the latest episode of coral development during this sea-level high-stand and is considerably more precise. In contrast, the initiation of the MIS 7.5 sea-level high-stand shortly after $248.9 \pm 1.9 \mathrm{ka}$ at Argentarola significantly pre-dates both the northern hemisphere insolation maximum at $\sim 241 \mathrm{ka}$ and the earliest recorded MIS 7.5 coral reef growth at Henderson Island of $240.3 \pm 0.8 \mathrm{ka}$ (Fig. 8). Several factors may explain this discrepancy. First, the speleothem maybe affected by diagenesis whereby the youngest growth episode close to the edge of the hiatus has been lost, although this is commonly a larger problem for calcite re-growth after a hiatus. Second, a considerable time-lag may have existed between the cessation of speleothem growth at Argentarola, while relative sea-level was still $\sim 18 \mathrm{~m}$ below present sea-level, and the timing of onset of the MIS 7.5 sea-level high-stand when Henderson Island's fossil reefs formed. Third, because of the remoteness 


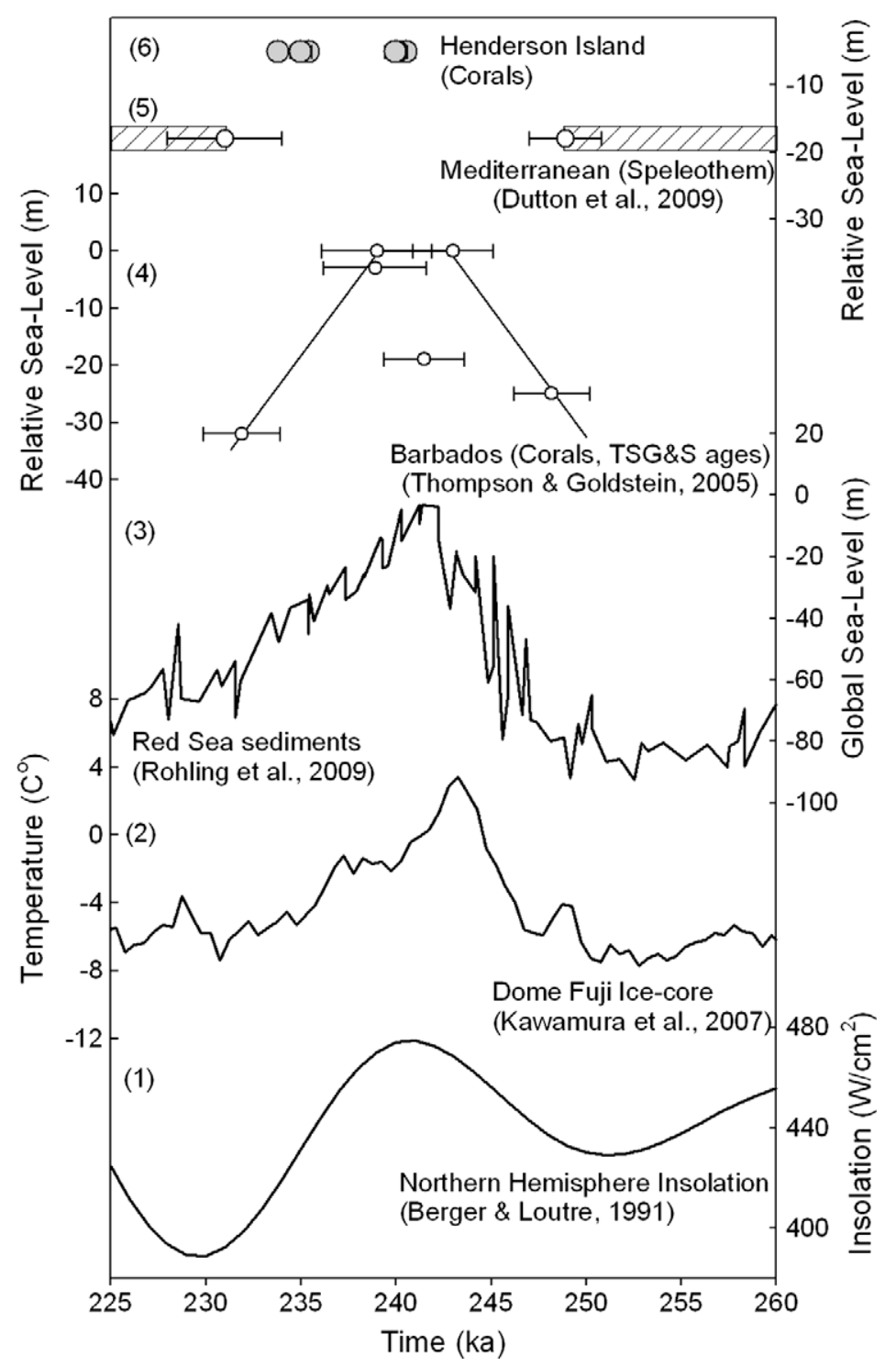

Fig. 8. Records of sea-level and climate variability for the MIS 7.5 interstadial period (260-225 ka). (1) Summer solar insolation predictions for latitude $65^{\circ} \mathrm{N}$, which according to the Milankovtich theory of climate change (Berger and Loutre, 1991; Milankovitch, 1941), drive Quaternary glacial-interglacial climate variability; (2) the Dome Fuji Antarctic ice-core record of local air temperature, which has been assigned a chronology based on orbital tuning and measurements of $\mathrm{O}_{2} / \mathrm{N}_{2}$ trapped in air, a proxy for local summer insolation (Kawamura et al., 2007); (3) highresolution global sea-level reconstructions derived from the $\delta^{18}$ O signatures of Red Sea sediment cores (Rohling et al., 2009; Siddall et al., 2003). The $\delta^{18} \mathrm{O}$ records were translated into global sea-level using a complex hydraulic model for the exchange of water between the Red Sea and the open ocean. A chronology was assigned to the Red Sea records based on a combination of radiometric control points and synchronization with orbitally-tuned Antarctic ice core records; (4) relative sea-level constraints derived from fossil coral reefs at Barbados, based upon a compilation of open-system U-series ages derived using the TSG\&S model and reported in Thompson and Goldstein (2005); (5) minimum relative sea-level constraints derived from paleo-speleothem growth at Argentarola, Italy. The timing of growth is constrained by a suite of conventional U-series ages reported in Dutton et al. (2009). These observations suggest that the MIS 7.5 sea-level high-stand was at most $-18 \mathrm{~m}$ below present sea-level between 249 and 231 ka relative to the Argentarola coastline; (6) constraints on the timing and duration of the MIS 7.5 sea-level high-stand, based upon a compilation of U-series observations for Henderson Island's fossil coral reefs reported in the present study. The error bars are $2 \sigma$.

of Henderson Island, there may be a lag between the onset of the sea-level high-stand and the start of reef development because of coral dispersal and recolonization limitations, although an explanation of this type is difficult to reconcile with the $\sim 8 \mathrm{ka}$ age difference between the Argentarola and Henderson Island observations. Forth, given the sparseness of coral growth on Henderson Island during MIS 7.5, it is possible that a sampling bias has occurred, whereby fossil corals formed during early MIS 7.5 have not been analyzed in this study.

\subsection{Marine Isotope Stage 9 U-series observations for Henderson Island}

In the present study, samples collected from the fossil lagoon, East Beach and North Beach during the 2003 expedi- 
tion to Henderson Island and sub-samples from several of the corals reported in Stirling et al. (2001) were dated via the U-series chronometer. These new U-series observations are compiled with the observations reported previously in Stirling et al. (2001) to constrain the timing of relative sea-level change at Henderson Island during MIS 9.

A significant number of the Henderson Island MIS 9 samples reported in Stirling et al. (2001) appear to have experienced minimal alteration, and pristine samples have $\delta^{234} U_{i}$ that overlap the modern seawater value (Stirling et al., 2001). Importantly, these U-series observations were derived using older half-life values (De Bievre et al., 1971; Jaffey et al., 1971; Meadows et al., 1980), but the present study adopts the more recent half-life estimates of Cheng et al. (2000). Recalculation to the newer half-lives shifts the $\delta^{234} \mathrm{U}_{\mathrm{i}}$ systematically so that none of these samples have $\delta^{234} U_{i}$ overlapping the modern marine value (Fig. 9). The dependence of the back-calculated $\delta^{234} \mathrm{U}_{\mathrm{i}}$ on the U-series half-lives highlights the importance of verifying accuracy in these determinations for the selection of reliable samples (Stirling and Andersen, 2009). Considering both the U-series results from the present study and the re-calculated observations from Stirling et al. (2001), the dataset as a whole displays open-system trends towards elevated $\left[{ }^{230} \mathrm{Th} /{ }^{238} \mathrm{U}\right]_{\text {act }}-\delta^{234} \mathrm{U}$ away from the modern $\delta^{234} \mathrm{U}_{\mathrm{i}}$ composition, however, the best preserved samples (and subsamples) appear to have identical, but potentially slightly elevated, $\delta^{234} \mathrm{U}_{\mathrm{i}}$ centered around $152 \pm 2 \%$ (Fig. 9). In a similar manner to the discussion in Section 5.2 for the MIS 7.5 samples, it is possible that these MIS 9 samples are unaltered and suggest that the marine $\delta^{234} U$ may have been $152 \pm 2 \%$ as opposed to $147 \%$ o (Stirling and Andersen, 2009) during MIS 9. However, further observations are required to confirm or refute this suggestion, and the possibility remains that all samples have experienced minor diagenesis, shifting the $\delta^{234} U_{\mathrm{i}}$ of even 'pristine' samples towards marginally elevated values.

Below, fossil corals sampled from the MIS 9 reef units will be discussed in the context of both their conventional closedsystem and open-system U-series ages. Samples analysed only once will not be evaluated further, as the direction and magnitude of the U-Th open-system shifts occurring within the coral skeleton cannot be accessed on the basis of single observations alone. Exceptions to this are samples belonging to reef units for which the open-system U-series trends have already been well constrained that can be directly compared with stratigraphically similar corals.

\subsubsection{Conventional U-series ages}

There are several ways to estimate the reliability of the conventional U-series ages of the MIS 9 corals from Henderson Island:

(1) Following other studies, corals with $\delta^{234} U_{i}$ lying within "acceptable" limits of the modern marine value (e.g. $\delta^{234} U_{\text {i-acceptable }}=147 \pm 4 \%$ ) may be considered to have reliable ages (e.g. Gallup et al., 1994; Stirling et al., 1998). In this scenario using a fixed screening criterion, the linear open-system trends shown by the Henderson Island samples can be used as a guide for defining the range of acceptable $\delta^{234} U_{\mathrm{i}}$. Samples with a $\delta^{234} \mathrm{U}_{\mathrm{i}}$ exceeding the
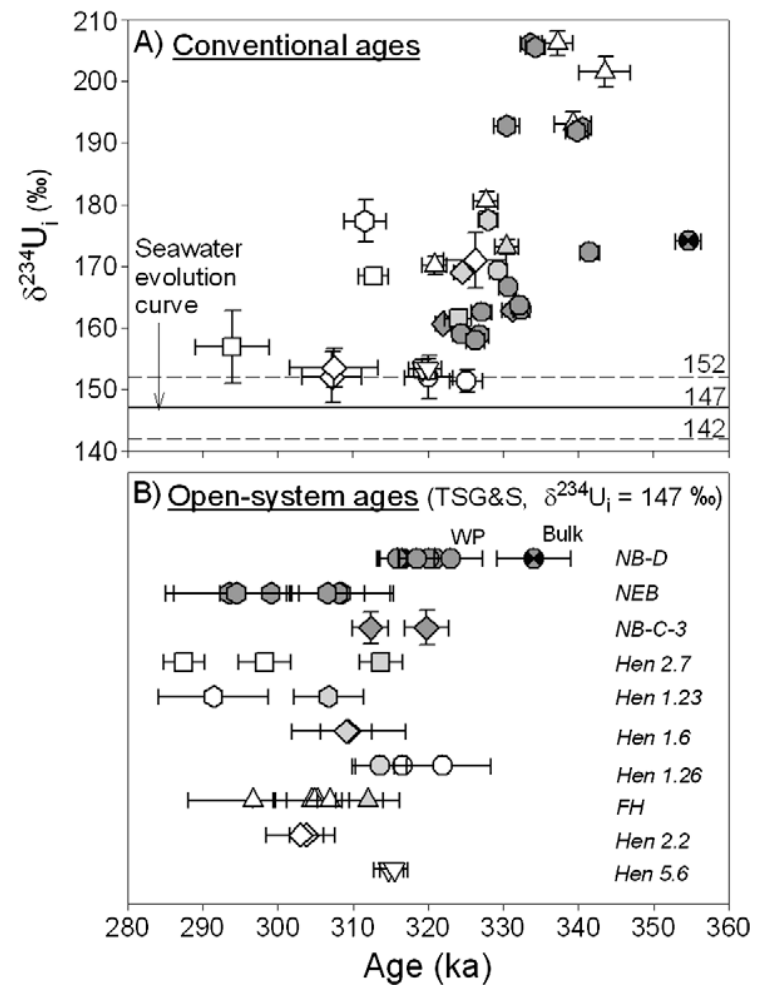

Fig. 9. U-series observations for MIS 9 fossil reefs on Henderson Island displayed as (A) U-series age versus $\delta^{234} \mathrm{U}_{\mathrm{i}}$ (omitting subsamples with anomalously low $\left[{ }^{230} \mathrm{Th} /{ }^{238} \mathrm{U}\right]_{\text {act }}$ ) and (B) TSG\&S open-system U-series ages for the same samples. Only corals analysed in replicate, on the basis of multiple measurements of sub-samples, or samples from clearly defined reef units that are likely to be of the same origin and age, are plotted. White symbols represent observations reported in Stirling et al. (2001) and grey symbols denote results from this study. The error bars are $2 \sigma$. Isochrons and three different seawater evolution curves $\left(\delta^{234} \mathrm{U}_{\mathrm{i}}=142 \%, 147 \%\right.$ and $152 \%$ ) are shown for reference. In A) replicate measurements of Hen 5.6, Hen 2.2 and Hen 1.26 have both similar $\delta^{234} U_{i}(152 \pm 2 \%)$ and the lowest $\delta^{234} \mathrm{U}_{\mathrm{i}}$ of the entire dataset. The 'bulk' sub-sample of NBD-1 does not follow the same sub-linear U-series open-system trend as 'wall' fragments of the same coral (see the main text for discussion). In (B) most of the TSG\&S open-system ages for subsamples of the same coral and/or corals from the same unit are overlapping within the limits of their $2 \sigma$ uncertainties. Exceptions are provided by Porites sample Hen 2.7, wall fractions of Faviidae coral NB-C-3, Hen 1.23 and the bulk sample of the Faviidae (NB-D-1) coral sampled from the NB-D unit (see the main text for discussion).

MIS 9 marine value by $2 \%$ are likely to have a conventional U-series age about $1.5 \mathrm{ka}$ older than the true age (Fig. 7). Assuming in the first instance that the MIS 9 marine $\delta^{234} \mathrm{U}$ was the same as the present day value, we consider samples with $\delta^{234} \mathrm{U}_{\mathrm{i}}=147 \pm 2 \%$ to be reliable, having conventional $U$-series ages that are accurate to within their approximate $\pm 1.5 \mathrm{ka}$ quoted uncertainties. Then the "unaltered' samples at Henderson Island that have $\delta^{234} U_{i}$ values centered about $152 \pm 2 \%$ do not lie within the "acceptable" range.

(2) Alternatively, taking the data at face value and assuming the marine $\delta^{234} \mathrm{U}$ was marginally higher than the present 
day composition during MIS 9 and equal to $152 \%$, then it is possible to adopt an alternative $\delta^{234} \mathrm{U}_{\mathrm{i}}$ criterion whereby acceptable ages lie within $2 \%$ of this composition $\left(\delta^{234} U_{\text {i-acceptable }}=152 \pm 2 \%\right.$. In this case, conventional U-series ages assessed as reliable are obtained for Hen 2.2 $(307 \pm 1 \mathrm{ka})$, Hen $1.26(323 \pm 3 \mathrm{ka})$ and Hen 5.6 $(320 \pm 1 \mathrm{ka})$ (Fig. 9). It should be noted that the above $2 \sigma$ age uncertainties assigned to the Henderson Island samples are based on the external variability of a minimum of two sub-samples (with overlapping $\delta^{234} U$ and $\left[{ }^{230} \mathrm{Th} /{ }^{238} \mathrm{U}\right] \mathrm{ra}-$ tios), as opposed to the internal errors associated with each individual measurement. The only other sample with a $\delta^{234} \mathrm{U}_{\mathrm{i}}$ overlapping $152 \pm 2 \%$ is one sub-sample of Hen 2.7 $(294 \pm 5 \mathrm{ka})$ that was previously tentatively correlated with prolonged MIS 9.1 interglacial reef growth or with the MIS 8.5 interstadial event (Stirling et al., 2001). Here we exclude this result for Hen 2.7 because two additional sub-samples of this coral, one conducted in Stirling et al. (2001) and the other in this study, yield significantly different U-series ages and show U-Th heterogeneity that does not follow the typical linear open-system relationship between $\delta^{234} U$ and $\left[{ }^{230} \mathrm{Th} /{ }^{238} \mathrm{U}\right]_{\text {act }}$ that is exhibited by the majority of Henderson Island's fossil corals (Fig. 9).

(3) From (1) and (2) above, it is clear that there is potential to bias the range of "acceptable" ages towards inaccurate values without an accurate knowledge of the marine $\delta^{234} U$ history of the oceans. For the selection of reliable MIS 9 samples from Henderson Island, overlap in the $\delta^{234} U_{i}$ of several corals (Hen 1.26, Hen 2.2 and Hen 5.6), which also display the lowest $\delta^{234} U_{i}$ centred about $152 \%$, argue that criterion (2) above, whereby $\delta^{234} U_{\text {i-acceptable }}=152 \pm 2 \%$, is valid. Thus for localities and time periods for which a limited knowledge of the marine $\delta^{234} \mathrm{U}$ is available, it may be desirable to adjust the $\delta^{234} U_{\mathrm{i}}$ criterion so that it that takes into account uncertainty in the marine $\delta^{234} \mathrm{U}$ at the time the corals formed. This is similar to the approach proposed for the calculation of open-system ages that are presently anchored by the modern marine $\delta^{234} \mathrm{U}$ of $147 \%$. This would be especially important if the selection of reliable U-series ages changes when the $\delta^{234} \mathrm{U}$ screening criterion is centered about different marine compositions. A $\delta^{234} \mathrm{U}_{\mathrm{i}}$ criterion of this type could be achieved by propagating an additional error through the age calculations over and above the analytical contribution, using the open-system models as a guide for determining the magnitude of this uncertainty. For example, in the TSG\&S open-system model, each per mill offset in the marine $\delta^{234} \mathrm{U}$ from the modern value during MIS 9 corresponds to a $\sim 0.7 \mathrm{ka}$ shift in the open-system age calculation (Fig. 7). A similar magnitude of error could be integrated into the screened conventional ages if the uncertainty in the screening range exceeds the measured uncertainty. For instance, if a screening criterion of $147 \pm 4 \%$ is used for MIS 9 samples, then an additional error of $\sim 2.8 \mathrm{ka}$ would be incorporated into the quoted age uncertainties.

\subsubsection{Open-system U-series ages}

Open-system U-series ages for the MIS 9 corals from Henderson Island have been derived using the TSG\&S, $\mathrm{V} \& \mathrm{~F}$, and linear regression models assuming, when required, a marine $\delta^{234} U$ of $147 \%$ at the time the samples formed. Unless stated otherwise, the reported uncertainties are based on the $2 \sigma$ analytical errors only. This allows the performance of the open-system models to be directly compared when considering the reproducibility of ages between (1) different corals from the same reef unit that are expected to have similar true ages, and (2) different sub-samples of the same coral with a given true age. Although not critical for the above comparison, it is important to note that the open-system age derivations become systematically older by $\sim 3.5 \mathrm{ka}$ if the calculations are instead based upon a slightly higher marine $\delta^{234} \mathrm{U}$ of $152 \%$.

Previous open-system studies of Henderson Island's fossil corals observed a systematic difference between the TSG\&S and V\&F open-system ages when both models were applied to the same suite of U-series observations, reported in Stirling et al. (2001), for MIS 9 corals from the fossil lagoon (FH unit). In detail, conventional U-series ages of the $\mathrm{FH}$ unit ranged from 320 to $345 \mathrm{ka}$ and their corresponding $\delta^{234} \mathrm{U}_{\mathrm{i}}$ were elevated, spanning 170-210\% (Stirling et al., 2001). Applying both models to this dataset resulted in open-system ages that showed considerably less scatter compared with the conventional U-series ages for the same set of samples, but there is a lack of consistency between the two sets of model results. Specifically, the TSG\&S model yields open-system ages ranging from $297 \pm 9$ to $307 \pm 7 \mathrm{ka}$, whereas the $\mathrm{V} \& \mathrm{~F}$ model gives rise to considerably younger open-system ages centered around $282+5 /-9$ ka. Furthermore, both open-system models have recently been applied to U-series data acquired for Henderson Island's older MIS 15 reefs, which have conventional U-series ages ranging from $\sim 600 \mathrm{ka}$ to beyond the closed-system limit of the U-series chronometer and $\delta^{234} \mathrm{U}$ ranging from $150 \%$ to $>300 \%$ or beyond the closed-system limit of the chronometer (Andersen et al., 2008). Similarly, the majority of open-system U-series ages acquired using the TSG\&S model are centered about $\sim 600 \mathrm{ka}$, whereas open-system ages derived using the V\&F model are beyond the $\sim 800 \mathrm{ka}$ upper limit of the U-series chronometer and are undefined (Andersen et al., 2008). The sizeable offset between the two open-system model outputs, despite the fact that both models are based on $\alpha$-recoil principles must be reconciled. It is also shown in Andersen et al. (2008) that the assumptions underpinning the V\&F model are not necessarily valid for samples older than $500 \mathrm{ka}$, and it appears that the model may suffer from similar limitations, albeit less amplified, at $\sim 300 \mathrm{ka}$. This may be a consequence of the $\alpha$-recoil factors used in the V\&F model being different from those used in the TSG\&S model (Thompson et al., 2003).

In this study, the most comprehensively dated reef section was North Beach reef unit NB-D where fossil corals were sampled from an elevation of $5 \pm 1 \mathrm{~m}$ above present MSL (Fig. 2). The majority of U-series measurements from the NB-D section yielded moderately elevated $\delta^{234} U_{i}(\sim 158$ $175 \%$ ) compared with the $\delta^{234} \mathrm{U}$ of modern seawater and conventional U-series ages ranging from $\sim 325$ to $\sim 340 \mathrm{ka}$ (Fig. 9). With the exception of only two data points, which exhibit shifts in $\left.{ }^{230} \mathrm{Th} /{ }^{238} \mathrm{U}\right]$ act towards anomalously low values, all dated Faviidae "wall" samples from the NB-D section appear to follow an approximately linear correlation 
between $\left[{ }^{230} \mathrm{Th} /{ }^{238} \mathrm{U}\right]_{\text {act }}$ and $\delta^{234} \mathrm{U}$ towards elevated values (Fig. 9), as is usually observed at fossil reef settings. This implies that the majority of conventional U-series ages are likely to be shifted towards anomalously old values compared with the true ages of these samples. Importantly, this broadly linear trend between $\left[{ }^{230} \mathrm{Th} /{ }^{238} \mathrm{U}\right]_{\text {act }}$ and $\delta^{234} \mathrm{U}$ in the NB-D samples makes it possible to test the performance of different open-system models for this reef unit, similar to the discussion above for the FH unit. The TSG\&S model yields open-system U-series ages ranging from $316 \pm 2$ to $323 \pm 4 \mathrm{ka}$ for the NB-D wall samples. The linear regression model gives rise to a comparable average age for the NB-D reef unit of $311+8 /-11 \mathrm{ka}$. However, a markedly different mean open-system age of $280+2 /-4$ ka is obtained by applying the V\&F model to the NB-D dataset. The good agreement between the Linear Regression and the TSG\&S open-system models for the NB-D unit may also suggest that these two approaches are more reliable than the V\&F model. These observations clearly imply that even if the scatter exhibited by the open-system model ages is dramatically reduced in comparison to the conventional U-series ages, accuracy need not necessarily follow. Thus other criteria for reliability, aside from improved reproducibility of the model ages, must be implemented when assessing open-system age reliability. This could include, for example, (1) a comparison of the open-system results with conventional U-series ages for well-preserved corals from the same coral reef unit to ensure mutual agreement and coherency between the two approaches, and (2) an assessment of reproducibility on the basis of multiple measurements of sub-samples from the same coral, in addition to the usual a priori and a posteriori selection criteria outlined in Section 1.

We consider the TSG\&S model to be the best performing open-system model for the fossil corals on Henderson Island, specifically due to the ability to obtain reasonable opensystem U-series age estimates for many of the MIS 15 corals (Andersen et al., 2008). In this respect Henderson Island may be unique compared to other localities, possibly related to both (1) the remote geographical position of Henderson Island so that it is isolated from terrestrial sources of detrital material containing additional sources of extraneous ${ }^{232} \mathrm{Th}$, ${ }^{238} \mathrm{U},{ }^{234} \mathrm{U}$ and ${ }^{230} \mathrm{Th}$, and (2) the predominantly carbonate structure of the island, which may limit diagenesis, and thereby the source of redistributed U-series $\alpha$-recoil products, to one systematic mechanism linked to carbonate dissolution. In addition to the comprehensive suite of U-series results for the NB-D unit discussed above, TSG\&S open-system ages have also been acquired for the stratigraphically well-defined FH and NEB units. For each unit, the sampled corals are believed to have formed at approximately the same time, therefore, consistency between the open-system ages of the different corals is expected. In this regard, TSG\&S open-system ages for the $\mathrm{FH}$ unit are reasonably self-consistent and range from $297 \pm 9$ to $312 \pm 4 \mathrm{ka}$, as are those for the NEB unit, which range from $294 \pm 8$ to $308 \pm 7 \mathrm{ka}$. For seven independent samples, TSG\&S open-system model ages have been obtained in replicate for different sub-samples of the same coral (Fig. 9) to further evaluate the performance of the model. In a similar manner to the conventional ages, the age uncertainties are based on the external variability of a minimum of two samples, as opposed to the higher precision internal errors assigned to individual sub-samples. For three of these samples (NB-C-3, Hen 2.7 and Hen 1.23), the replicate TSG\&S open-system ages for the different sub-samples do not overlap within the magnitude of their error limits, indicating that the assigned age uncertainties have been under-estimated, or that other open-system processes have occurred that have not been taken into account by the model. These three samples will not be discussed further (Fig. 9). Other TSG\&S open-system model ages were obtained in replicate for multiple sub-samples of Hen 1.6 (309 $\pm 4 \mathrm{ka})$, Hen $1.26(318 \pm 4 \mathrm{ka})$, Hen $2.2(303 \pm 1 \mathrm{ka})$ and Hen 5.6 $(315 \pm 2 \mathrm{ka})$. For these four corals, the open-system ages for the different sub-samples overlap within the range of their uncertainties (Fig. 9).

\subsubsection{Relative sea-level during MIS 9 at Henderson Island}

The above results from the TSG\&S open-system model are considered in comparison to conventionally-dated U-series observations for well-preserved samples from stratigraphically comparable fossil reef units. Two conventionally dated samples, Hen 5.6 and Hen 1.26, both of which are assumed to be unaltered, have overlapping U-series ages of $320 \pm 1$ and $323 \pm 3 \mathrm{ka}$, respectively. The youngest reliable sample, Hen 2.2 , has a conventional U-series age of $307 \pm 1 \mathrm{ka}$. These ages appear to be correlated with the MIS 9.3 and 9.1 interglacial periods (Stirling et al., 2001). The TSG\&S open-system ages for sample Hen 5.6 (315 $\pm 2 \mathrm{ka})$, Hen 1.26 (318 $\pm 4 \mathrm{ka})$ and Hen $2.2(303 \pm 1 \mathrm{ka})$ are all shifted by $\sim 3.5 \mathrm{ka}$ towards younger values in comparison to the conventional ages when a seawater $\delta^{234} \mathrm{U}$ value of $147 \%$ is adopted for the open-system calculations.

The FH unit, with TSG\&S open-system ages ranging from $297 \pm 8$ to $312 \pm 4 \mathrm{ka}$, and samples Hen 5.6 and Hen 1.26 , with respective open-system ages of $315 \pm 2$ and $318 \pm 4 \mathrm{ka}$, occur at comparable stratigraphic heights of 24-28 $\mathrm{m}$ above MSL. It is possible that the generally younger ages of the FH unit represent a separate sea-level oscillation towards the end of MIS 9.3 that was of comparable magnitude to the earlier event forming Hen 5.6 and Hen 1.26. However, other studies have suggested that the errors assigned to the TSG\&S model ages are underestimated (Andersen et al., 2008; Scholz and Mangini, 2006, 2007). This is also indicated by the inconsistent results shown by some of the samples analysed in replicate, as discussed above. If expanded by a factor of two, the TSG\&S ages of the FH unit would be identical, within error, to the TSG\&S ages for samples Hen 1.26 and Hen 5.6. Therefore, it is equally likely that the FH unit formed contemporaneously with samples Hen 5.6 and Hen 1.26 during a single sea-level event, particularly given their similar stratigraphic heights. It should be reiterated that the open-system constraints in this study are based on replicate measurements for a minimum of two sub-samples with overlapping TSG\&S ages; sub-samples that do not give identical results are considered unreliable and have already been rejected from further consideration. In addition, Dutton et al. (2009) have emphasised the likelihood of inaccuracy in the TSG\&S open-system ages reported in Thompson and Goldstein (2005) for a MIS 7 Barbados reef transect, on the basis that the analysed samples are characterised by very 


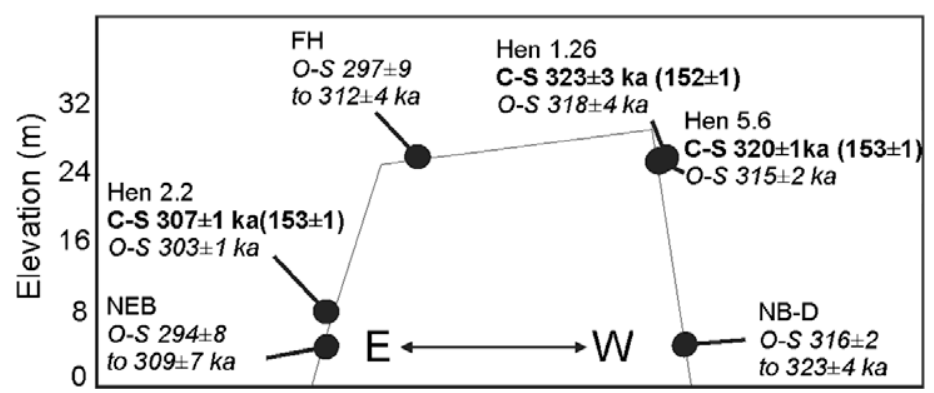

Fig. 10. Schematic cross-section of Henderson Island, showing the approximate location, height (above present mean sea-level), and U-series age of the dated MIS 9 samples and coral reef units shown in Fig. 9. Ages are shown both as closed-system (C-S) estimates and TSG\&S opensystem estimates (O-S). The TSG\&S open-system ages assume a $\delta^{234} \mathrm{U}$ of $147 \%$ and are $\sim 3.5$ ka younger than the C-S estimates for the same samples.

elevated $\delta^{234} U_{i}(>300 \%)$. An increased sensitivity of the robustness of the TSG\&S open-system ages with elevated $\delta^{234} U_{i}$ may indicate that the age uncertainties assigned to samples with higher $\delta^{234} \mathrm{U}_{\mathrm{i}}$ should be increased accordingly. This effect may be manifested in the open-system results for the FH unit given their relatively high $\delta^{234} U_{i}(170-210 \%$ ).

Similarly, the NB-D unit with TSG\&S open-system ages ranging from $316 \pm 2$ to $323 \pm 4 \mathrm{ka}$, the NEB unit with open-system ages ranging from $294 \pm 8$ to $308 \pm 7 \mathrm{ka}$, and Hen 2.2 and Hen 1.6, with TSG\&S model ages of $303 \pm 1$ and $309 \pm 4 \mathrm{ka}$, respectively, are all of similar stratigraphic height and located 5-8 $\mathrm{m}$ above MSL (Fig. 10). The open-system ages for Hen $2.2(303 \pm 1 \mathrm{ka}$, $8 \mathrm{MSL}$ ) and Hen 1.6 (309 $\pm 2 \mathrm{ka}, 7 \mathrm{MSL})$, although similar, do not overlap, whereas the open-system ages for the NEB unit, dominated by larger age errors (294 \pm 8 to $309 \pm 7 \mathrm{ka}$ ), are identical to those obtained for both samples. The open-system ages for the best-preserved wall fragments of corals from the NB-D unit are considerably older $(316 \pm 2$ to $323 \pm 4 \mathrm{ka})$. The NB-D reef unit is dominated by dome-shaped Faviids and Porites corals (Fig. 2). This reef unit is believed to be analogous to reef structures across the entire Indo-Pacific region that have formed in a low energy environment within water depths of 0-15 m (Montaggioni, 2005). The NB-D results are identical, within error, to the TSG\&S open-system ages of $315 \pm 2$ and $318 \pm 4$ ka derived for the well-preserved North Beach corals Hen 5.6 and Hen 1.26, respectively, although these samples are located at stratigraphically higher elevations of 24 $26 \mathrm{~m}$ above MSL. In contrast to the FH samples discussed above, corals from the NB-D unit have only moderately elevated $\delta^{234} U_{i}$ of $\sim 158-172 \%$ and it is possible that the TSG\&S open-system ages and their associated error limits are more robust for this unit than for the FH unit. The $>20 \mathrm{~m}$ statigraphic difference between these two units therefore suggests a change in sea-level of this magnitude sometime during the several thousand year time-frame spanning both sets of ages (Fig. 10) if our inference regarding a limited depth range for coral growth is valid for Henderson Island's corals.

To summarize, the combined conventional and opensystem U-series results for Henderson Island's MIS 9 fossil reef complexes, reported in both the present study and in Stirling et al. (2001), are indicative of several discrete reef- building episodes. These appear to be correlated with the MIS 9.3 and 9.1 interglacial periods as follows, assuming the fossil corals grew up to the sea-surface (Fig. 11):

(1) Sea levels approached peak MIS 9.3 interglacial values near $322 \pm 3 \mathrm{ka}$ with high relative sea-levels at elevations of 24-26 m above present MSL at Henderson Island (based on the heights and conventional U-series ages of Hen 1.26 and Hen 5.6). It is likely that the MIS 9 FH unit formed during this coral development episode as well.

(2) Relative sea-level then fell $\sim 20$ to $\sim 5 \mathrm{~m}$ above present MSL near $318 \pm 5 \mathrm{ka}$, based on a comparison of the TSG\&S open-system U-series ages for Hen 1.26 and Hen 5.6 and the NB-D reef unit, however, our observations do not have sufficient resolution to allow the exact timing of this event to be constrained.

(3) Relative sea levels stabilized again near $\sim 8 \mathrm{~m}$ above present MSL at $\sim 307 \pm 1 \mathrm{ka}$ during MIS 9.1, based on the conventional U-series ages of Hen 2.2.

Apart from the U-series observations for Henderson Island, direct chronologies for sea-level change during MIS 9 derived from fossil coral reefs are limited to a few isolated $\mathrm{U}$-series estimates with large associated age uncertainties in excess of $\pm 5 \mathrm{ka}$ (Camoin et al., 2001; Galewsky et al., 1996). Coral reef chronologies aside, a combined $\delta^{18} \mathrm{O}$ and U-series study of aragonitic slope sediments from the Bahamas suggests that the onset of the MIS 9 interglacial may have started as early as $\sim 343 \mathrm{ka}$ (Henderson et al., 2006), pre-dating peak interglacial warming at $\sim 335 \mathrm{ka}$ in orbitally-tuned records by several thousand years (Fig. 11). The earliest reliably recorded phase of MIS 9 reef growth on Henderson Island indicates that peak interglacial sea-levels during MIS 9.3 were most likely attained near $322 \pm 3 \mathrm{ka}$. Therefore, assuming ecological lags have not significantly restricted coral development at Henderson Island, and no sampling biases have influenced the U-series observations, no evidence for an early onset of the MIS 9 interglacial reef growth that significantly pre-dates the $\sim 335 \mathrm{ka}$ insolation maximum is indicated by our dataset. However, in a similar manner to the MIS 7 data discussed in Section 5.2, the combined uncertainties in the U-series ages for the Henderson Island corals and Bahamian aragonitic slope sediments prevents a rigorous comparison of the 


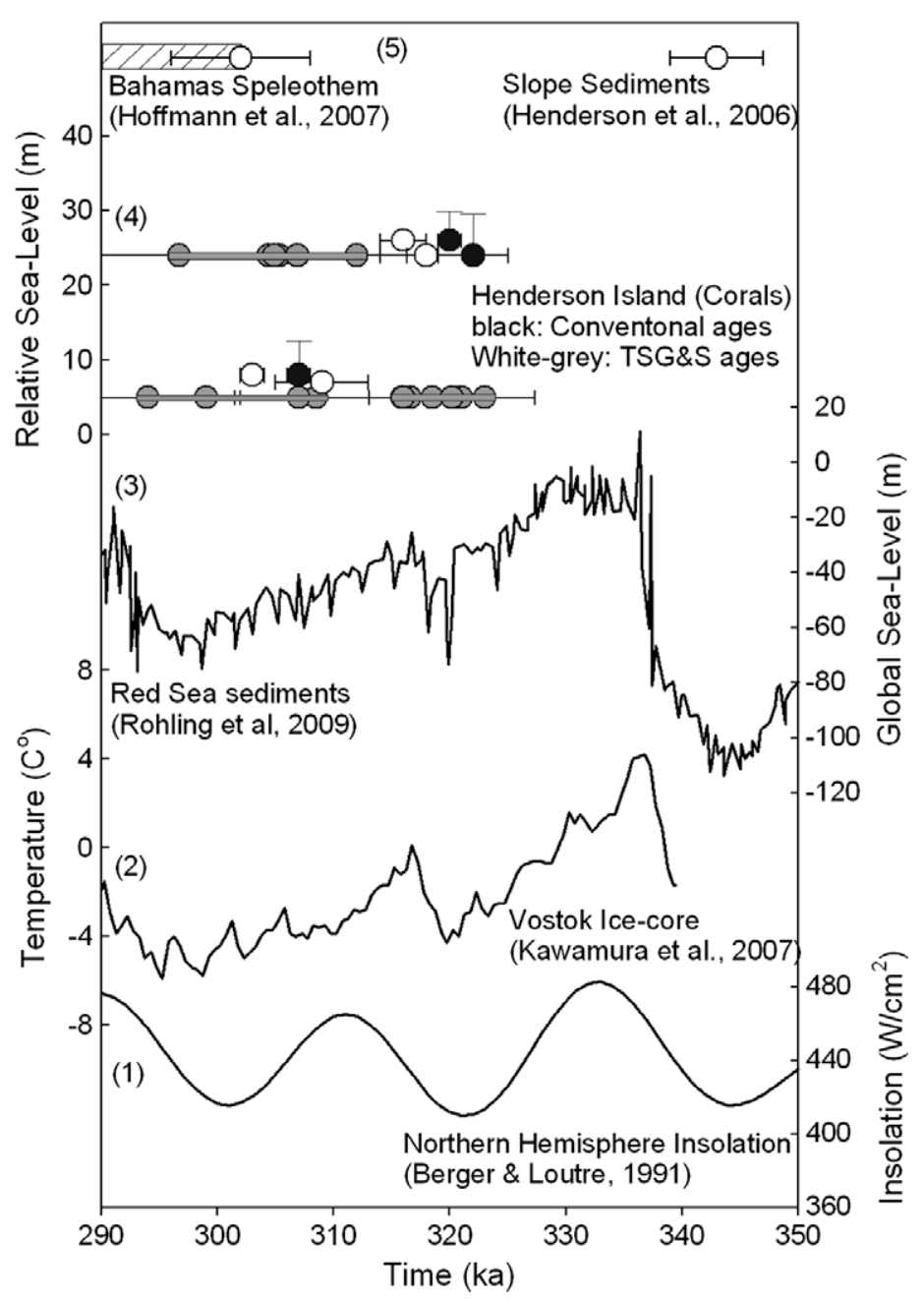

Fig. 11. Records of sea-level and climate variability for the MIS 9 interglacial interval (350-290 ka). (1) Milankovtich summer solar insolation predictions for latitude $65^{\circ} \mathrm{N}$ (Berger and Loutre, 1991; Milankovitch, 1941); (2) the Dome Fuji Antarctic ice-core record of local air temperature, which has been assigned a chronology based on orbital tuning and measurements of $\mathrm{O}_{2} / \mathrm{N}_{2}$ trapped in air, a proxy for local summer insolation (Kawamura et al., 2007). (3) High-resolution global sea-level reconstructions derived from the $\delta^{18} \mathrm{O}$ signatures of Red Sea sediment cores (Rohling et al., 2009; Siddall et al., 2003). The $\delta^{18} \mathrm{O}$ records were translated into global sea-level using a complex hydraulic model for the exchange of water between the Red Sea and the open ocean. A chronology was assigned to the Red Sea records based on a combination of radiometric control points and synchronization with orbitally-tuned Antarctic ice core records; (4) constraints on the timing, duration and character of relative sea-level at Henderson Island, based upon a compilation of U-series observations for Henderson Island's MIS 9 fossil coral reefs reported in the present study and in Stirling et al. (2001). Conventional U-series age constraints are indicated by the black symbols, while the white symbols (for individual samples) and grey symbols (for reef units) represent TSG\&S open-system U-series age constraints derived using the Thompson et al. (2003) open-system model (see Fig. 10). A $+6 \mathrm{~m}$ uncertainty has been assigned to the relative sea-level heights to reflect uncertainty in the water depth in which the fossil coral grew; (5) The MIS 8/9 glacial-interglacial transition, derived from paleo-speleothem growth at the Bahamas (Hoffmann et al., 2007a), and sea-level constraints based upon the combined $\delta^{18} \mathrm{O}$ signature and U-series chronology of aragonitic slope sediments from the Bahamas, which suggest an early onset of MIS 9 (Henderson et al., 2006).

two datasets. Regarding the termination of the MIS 9 interglacial period, U-series dating of paleo-speleothem growth at the Bahamas suggests that a major sea-level regression occurred at $302 \pm 6 \mathrm{ka}$, coincident with the MIS 9/8 interglacial-glacial transition (Hoffmann et al., 2007a,b). This result is in very good agreement with the Henderson Island U-series observations, which constrain the latest phase of MIS 9 interglacial reef growth to $307 \pm 1 \mathrm{ka}$ (Fig. 11).

As discussed in Section 5.2, conversion of the above-described MIS 9 relative sea-level observations for Henderson Island to global estimates of eustatic sea-level requires gla- cio-hydro-isostatic and lithospheric flexural modelling, and will be presented in a separate study. However, because these isostatic adjustments are slow and systematic, millennialscale oscillations in eustatic sea-level are expected to be faithfully preserved in the relative sea-level record for Henderson Island. In this regard, comparisons can be made with reconstructions of continuous global sea level based on the $\delta^{18} \mathrm{O}$ measurements of Red Sea sediments (Rohling et al., 2009; Siddall et al., 2003), although the timing of events may be incorrect in the Red Sea curve, as it has been dated by correlation to the EPICA (EDC3) ice-core orbitally-tuned 
chronology (Parrenin et al., 2007). The modelled Red Sea record suggests maximum MIS 9.3 sea-levels near modern levels. Furthermore, the resolution of the Red Sea sea-level curves suggests that oscillations in sea level, in excess of $20 \mathrm{~m}$ during MIS 9, are possible on millennial time-scales. This is consistent with the magnitude of the oscillations recorded in the Henderson Island fossil reef sequences, at elevations of $+24-26 \mathrm{~m}$ for MIS 9.3 and $+8 \mathrm{~m}$ for MIS 9.1 with respect to present day MSL, separated by a $\sim 20 \mathrm{~m}$ fall in relative sea level at the end of MIS 9.3 (Fig. 11).

\section{CONCLUSIONS}

New high-precision U-series age determinations for fossil reef complexes on Henderson Island in the South Pacific yield new information on the timing, duration and character of sea level change during MIS 7 and MIS 9.

(1) Conventional U-series ages for well-preserved fossil corals from the MIS 7 reefs indicate that minor patch reef development occurred at $240.3 \pm 0.8 \mathrm{ka}$ and $234.7 \pm 1.3 \mathrm{ka}$, in accordance with the timing of the MIS 7.5 interstadial event $(245-230 \mathrm{ka})$. The timing of MIS 7.5 reef growth at Henderson Island appears to slightly postdate the $\sim 241 \mathrm{ka}$ timing of peak summer solar insolation at latitude $65^{\circ} \mathrm{N}$ and is thus consistent with the Milankovitch theory of climate change. In addition, the MIS 7.5 fossil corals have associated $\delta^{234} U_{\mathrm{i}}$ values that lie within $\pm 1 \%$ of the modern seawater composition of $147 \%$.

(2) New U-series ages for MIS 9 fossil reefs support the earlier findings of Stirling et al. (2001), providing evidence of prolific coral reef development during a sea-level highstand occurring at $\sim 322 \mathrm{ka}$, most likely correlated with the MIS 9.3 interglacial period. Subsequent reef development during MIS 9.1 at $\sim 307 \mathrm{ka}$, while relative sea-level was $\sim 20 \mathrm{~m}$ lower than during MIS 9.3, are also recorded at Henderson Island. Glacio-hydro-isostatic rebound and lithospheric flexural modelling is required to convert these relative sea-level signatures into constraints on global eustatic sea-level.

(3) Despite the high degree of preservation displayed by most corals, some show signs of alteration, as well as considerable heterogeneity in U-series isotopic composition between different sub-samples of the same coral. This is particularly pronounced with respect to $\left[{ }^{230} \mathrm{Th} /{ }^{238} \mathrm{U}\right]_{\text {act }}$, which in some corals, exhibits appreciable (percent-level) shifts towards both anomalously high and low values, yielding respective U-series ages that are older and younger than the true ages. Importantly, these shifts in $\left[{ }^{230} \mathrm{Th} /{ }^{238} \mathrm{U}\right]$ act are not accompanied by a shift in $\delta^{234} \mathrm{U}$. This observation is not accounted for by any of the open-system U-series models based on the remobilization of $\alpha$-recoiled nuclides, and strongly indicates that the open-system approach to U-series dating should be used with extreme caution unless all diagenetic processes are well understood. The suitability of a paleo-reef site for the open-system approach should be assessed on a case-by-case basis and further investigations of U-series open-system behaviour in coral reef systems are warranted. The most robust approach to constraining the age of reef growth remains to consider the stratigraphic relationships and U-series systematics, including both conven- tional and open-system U-series ages, for a large dataset (including sub-samples of the same coral).

\section{ACKNOWLEDGMENTS}

We are grateful to the valuable support of Felix Oberli, Helen Williams and Sarah Woodland, as well as Urs Menet, Heiri Baur and Bruno Rütsche, and the rest of the IGMR group who expended time and effort to ensure the smooth running of the MCICPMS facilities at IGMR. Damian Kelleher, Alve Henricson and the crew of the Research Vessel 'Searcher' are gratefully thanked for their efforts in making the Henderson Island expedition a success. Thanks also to Judith Mackenzie and David Richards for discussions. M.B.A and C.H.S thank the organizers of the PALSEA (supported by IMAGES/PAGES) workshops: 'Empirical Constraints on Sea-Level Rise Over the Next Century at University of Bern and "Understanding Future Sea Level Rise: The challenges of dating past interglacials" at WHOI for our invited participation, as well as the attendees of this meeting for rigorous and stimulating discussions. We furthermore thank for constructive reviews from Laura Robinson, Alex Thomas and Yusuke Yokohama and the editorial handling by Mariam Barr-Matthews which great improved a previous version of the manuscript.

\section{REFERENCES}

Andersen M. B., Stirling C. H., Porcelli D., Halliday A. H., Andersson P. S. and Baskaran M. (2007) The tracing of riverine $\mathrm{U}$ in Arctic seawater with very precise ${ }^{234} \mathrm{U} /{ }^{238} \mathrm{U}$ measurements. Earth Planet. Sci. Lett. 259, 171-185.

Andersen M. B., Stirling C. H., Potter E. K. and Halliday A. N. (2004) Toward epsilon levels of measurement precision on ${ }^{234} \mathrm{U} /{ }^{238} \mathrm{U}$ by using MC-ICPMS. Int. J. Mass Spectrom. 237(23), 107-118.

Andersen M. B., Stirling C. H., Potter E. K., Halliday A. N., Blake S. G., McCulloch M. T., Ayling B. F. and O'Leary M. (2008) High-precision U-series measurements of more than 500,000 year old fossil corals. Earth Planet. Sci. Lett. 265, 229-245.

Ayling B. F., McCulloch M. T., Gagan M. K., Stirling C. H., Andersen M. B. and Blake S. G. (2006) $\mathrm{Sr} / \mathrm{Ca}$ and $\delta^{18} \mathrm{O}$ seasonality in a Porites coral from the MIS 9 (339-303 ka) interglacial. Earth Planet. Sci. Lett. 248(1-2), 462-475.

Bard E., Fairbanks R. G., Hamelin B., Zindler A. and Hoang C. T. (1991) U-234 Anomalies in corals older than 150,000 years. Geochim. Cosmochim. Acta 55(8), 2385-2390.

Bard E., Hamelin B., Arnold M., Montaggioni L., Cabioch G., Faure G. and Rougerie F. (1996a) Deglacial sea-level record from Tahiti corals and the timing of global meltwater discharge. Nature 382(6588), 241-244.

Bard E., Jouannic C., Hamelin B., Pirazzoli P., Arnold M., Faure G., Sumosusastro P. and Syaefudin (1996b) Pleistocene sea levels and tectonic uplift based on dating of corals from Sumba Island, Indonesia. Geophys. Res. Lett. 23(12), 1473-1476.

Bender M. L., Fairbanks R. G., Taylor F. W., Matthews R. K., Goddard J. G. and Broecker W. S. (1979) Uranium-series dating of the pleistocene reef tracts of barbados, West-Indies. Geol. Soc. Am. Bull. 90(6), 577-594.

Benton T. G. and Spencer T. (1995) The birds of Henderson Island - ecological-studies in a near pristine ecosystem. Biol. J. Linn. Soc. 56(1-2), 147-148.

Berger A. and Loutre M. F. (1991) Insolation values for the climate of the last 10000000 years. Quatern. Sci. Rev. 10(4), 297-317.

Bintanja R., van de Wal R. S. W. and Oerlemans J. (2005) Modelled atmospheric temperatures and global sea levels over the past million years. Nature 437(7055), 125-128. 
Blake S. G. (1995) Late quaternary history of Henderson Island, pitcairn group. Biol. J. Linn. Soc. 56(1-2), 43-62.

Broecker W. S. (1966) Absolute dating and astronomical theory of glaciation. Science 151(3708), 299-304.

Cabioch G., Camoin G. F. and Montaggioni L. F. (1999) Postglacial growth history of a French Polynesian barrier reef tract, Tahiti, central Pacific. Sedimentology 46(6), 985-1000.

Camoin G. F., Ebren P., Eisenhauer A., Bard E. and Faure G. (2001) A 300,000-yr coral reef record of sea level changes, Mururoa atoll (Tuamotu archipelago, French Polynesia). Palaeogeogr. Palaeoclimatol. Palaeoecol. 175(1-4), 325-341.

Chen J. H., Curran H. A., White B. and Wasserburg G. J. (1991) Precise chronology of the last interglacial period - U-234-Th230 data from Fossil Coral Reefs in the Bahamas. Geol. Soc. Am. Bull. 103(1), 82-97.

Cheng H., Edwards R. L., Hoff J., Gallup C. D., Richards D. A. and Asmerom Y. (2000) The half-lives of uranium-234 and thorium-230. Chem. Geol. 169(1-2), 17-33.

Chiu T. C., Fairbanks R. G., Mortlock R. A., Cao L., Fairbanks T. W. and Bloom A. L. (2006) Redundant Th-230/U-234/U-238, $\mathrm{Pa}-231 / \mathrm{U}-235$ and C-14 dating of fossil corals for accurate radiocarbon age calibration. Quatern. Sci. Rev. 25(17-18), 2431-2440.

Cutler K. B., Edwards R. L., Taylor F. W., Cheng H., Adkins J., Gallup C. D., Cutler P. M., Burr G. S. and Bloom A. L. (2003) Rapid sea-level fall and deep-ocean temperature change since the last interglacial period. Earth Planet. Sci. Lett. 206(3-4), 253-271.

Cutler K. B., Gray S. C., Burr G. S., Edwards R. L., Taylor F. W., Cabioch G., Beck J. W., Cheng H. and Moore J. (2004) Radiocarbon calibration and comparison to $50 \mathrm{kyr}$ BP with paired ${ }^{14} \mathrm{C}$ and ${ }^{230} \mathrm{Th}$ dating of corals from Vanuatu and Papua New Guinea. Radiocarbon 46(3), 1127-1160.

De Bievre P., Lauer K. F., Le Duigon Y., Moret H., Muschenborn G., Spaepen J., Spernol A., Vaninbroukx R. and Verdingh V. (1971) The half-life of 234-U. In Proc. Int. Conf. Chem. Nucl. Data, Measurement and Applications, Canterbury (ed. M. L. Hurrell). Inst. Civil Engineers, London, pp. 221-225.

Deschamps P., Doucelance R., Ghaleb B. and Michelot J. L. (2003) Further investigations on optimized tail correction and highprecision measurement of uranium isotopic ratios using multicollector ICP-MS. Chem. Geol. 201(1-2), 141-160.

Dorale J. A., Onac B. P., Fomos J. J., Gines A., Tiuccimei P. and Peate D. W. (2010) Sea-level highstand 8,000 years ago in Mallorca. Science 327(5967), 860-863.

Duncan R. A., McDougal I., Carter R. M. and Coombs D. S. (1974) Pitcairn Island - another Pacific Hot Spot. Nature 251(5477), 679-682.

Dutton A., Bard E., Antonioli F., Esat T. M., Lambeck K. and McCulloch M. T. (2009) Phasing and amplitude of sea-level and climate change during the penultimate interglacial. Nat. Geosci. 2, 355-359.

Edwards R. L., Cheng H., Murrell M. T. and Goldstein S. J. (1997) Protactinium-231 dating of carbonates by thermal ionization mass spectrometry: implications for quaternary climate change. Science 276(5313), 782-786.

Edwards R. L., Gallup C. D. and Cheng H. (2003) Uranium-series dating of marine and lacustrine carbonates. In Uranium-Series Geochemistry, vol. 52, pp. 363-405.

Eggins S. M., Grun R., McCulloch M. T., Pike A. W. G., Chappell J., Kinsley L., Mortimer G., Shelley M., Murray-Wallace C. V., Spotl C. and Taylor L. (2005) In situ U-series dating by laserablation multi-collector ICPMS: new prospects for Quaternary geochronology. Quatern. Sci. Rev. 24(23-24), 2523-2538.

Esat T. M., McCulloch M. T., Chappell J., Pillans B. and Omura A. (1999) Rapid fluctuations in sea level recorded at Huon
Peninsula during the penultimate deglaciation. Science 283(5399), 197-201.

Esat T. M. and Yokoyama Y. (2006) Variability in the uranium isotope composition of the oceans over glacial-interglacial timescales. Geochim. Cosmochim. Acta 70, 4140-4150.

Fietzke J., Liebetrau V., Eisenhauer A. and Dullo C. (2005) Determination of uranium isotope ratios by multi-static MICICP-MS: method and implementation for precise U- and Th-series isotope measurements. J. Anal. At. Spectrom. 20(5), 395-401.

Fruijtier C., Elliott T. and Schlager W. (2000) Mass-spectrometric U-234-Th-230 ages from the Key Largo Formation, Florida Keys, United States: constraints on diagenetic age disturbance. Geol. Soc. Am. Bull. 112(2), 267-277.

Galewsky J., Silver E. A., Gallup C. D., Edwards R. L. and Potts D. C. (1996) Foredeep tectonics and carbonate platform dynamics in the Huon Gulf, Papua New Guinea. Geology 24(9), 819-822.

Gallup C. D., Cheng H., Taylor F. W. and Edwards R. L. (2002) Direct determination of the timing of sea level change during termination II. Science 295(5553), 310-313.

Gallup C. D., Edwards R. L. and Johnson R. G. (1994) The timing of high sea levels over the past 200,000 years. Science 263(5148), 796-800.

Goldstein S. J. and Stirling C. H. (2003) Techniques for measuring uranium-series nuclides: 1992-2002. In Uranium-Series Geochemistry, vol. 52, pp. 23-57.

Gvirtzman G., Kronfeld J. and Buchbinder B. (1992) Dated coral reefs of southern Sinai (Red Sea) and their implication to late Quaternary sea levels. Mar. Geol. 108(1), 29-37.

Hamelin B., Bard E., Zindler A. and Fairbanks R. G. (1991) ${ }^{234} \mathrm{U} /{ }^{238} \mathrm{U}$ mass-spectrometry of corals - How accurate is the $\mathrm{U}-\mathrm{Th}$ age of the last interglacial period. Earth Planet. Sci. Lett. 106(1-4), 169-180.

Henderson G. M. (2002) Seawater $\left({ }^{234} U /{ }^{238} U\right)$ during the last 800 thousand years. Earth Planet. Sci. Lett. 199(1-2), 97-110.

Henderson G. M., Cohen A. S. and Onions R. K. (1993) U-234/U238 ratios and Th-230 ages for Hateruma atoll corals implications for coral diagenesis and seawater U-234/U-238 ratios. Earth Planet. Sci. Lett. 115(1-4), 65-73.

Henderson G. M., Robinson L. F., Cox K. and Thomas A. L. (2006) Recognition of non-Milankovitch sea-level highstands at 185 and 343 thousand years ago from U-Th dating of Bahamas sediment. Quatern. Sci. Rev. 25(23-24), 3346-3358.

Henderson G. M. and Slowey N. C. (2000) Evidence from U-Th dating against Northern Hemisphere forcing of the penultimate deglaciation. Nature 404(6773), 61-66.

Hoffmann D. L., Prytulak J., Richards D. A., Elliott T., Coath C. D., Smart P. L. and Scholz D. (2007a) Procedures for accurate $\mathrm{U}$ and $\mathrm{Th}$ isotope measurements by high precision MC-ICPMS. Int. J. Mass Spectrom. 264(2-3), 97-109.

Hoffmann D. L., Richards D. A., Smart P. L., Borton C. L. and Edwards R. L. (2007b) U-Th ages of multiple-phases of speleothem growth in the Bahamas and middle - late Pleistocene sea-level. EGU Geophys. Res. Abstr. 9, 08429.

Hughen K. A., Baillie M. G. L., Bard E., Beck J. W., Bertrand C. J. H., Blackwell P. G., Buck C. E., Burr G. S., Cutler K. B., Damon P. E., Edwards R. L., Fairbanks R. G., Friedrich M., Guilderson T. P., Kromer B., McCormac G., Manning S., Ramsey C. B., Reimer P. J., Reimer R. W., Remmele S., Southon J. R., Stuiver M., Talamo S., Taylor F. W., van der Plicht J. and Weyhenmeyer C. E. (2004) Marine04 marine radiocarbon age calibration, 0-26 cal kyr BP. Radiocarbon 46, $1059-1086$.

Irving R. A. (1995) Near-shore bathymetry and reef biotopes of Henderson Island, Pitcairn Group. Biol. J. Linn. Soc. 56(1-2), 309-324. 
Jaffey A., Flynn K., Glendenin L., Bentley W. and Essling A. (1971) Precision measurement of half-lives and specific activities of 235U and 238U. Phys. Rev. C4, 1889-1906.

Kawamura K., Parrenin F., Lisiecki L., Uemura R., Vimeux F., Severinghaus J. P., Hutterli M. A., Nakazawa T., Aoki S., Jouzel J., Raymo M. E., Matsumoto K., Nakata H., Motoyama H., Fujita S., Goto-Azuma K., Fujii Y. and Watanabe O. (2007) Northern Hemisphere forcing of climatic cycles in Antarctica over the past 360,000 years. Nature 448(7156), 912-U4.

Lambeck K., Esat T. M. and Potter E. K. (2002) Links between climate and sea levels for the past three million years. Nature 419(6903), 199-206.

Li W. X., Lundberg J., Dickin A. P., Ford D. C., Schwarcz H. P., McNutt R. and Williams D. (1989) High-precision massspectrometric uranium-series dating of cave deposits and implications for Paleoclimate studies. Nature 339(6225), 534-536.

Ludwig K. R., Simmons K. R., Szabo B. J., Winograd I. J., Landwehr J. M., Riggs A. C. and Hoffman R. J. (1992) Massspectrometric $230^{\mathrm{Th}}-234 \mathrm{U}-238 \mathrm{U}$ dating of the Devils-Hole Calcite Vein. Science 258(5080), 284-287.

Lundberg J. and Ford D. C. (1994) Late pleistocene sea-level change in the Bahamas from mass-spectrometric U-series dating of submerged speleothem. Quatern. Sci. Rev. 13(1), 1-14.

McNutt M. and Menard H. W. (1978) Lithospheric flexure and uplifted atolls. J. Geophys. Res. 83(NB3), 1206-1212.

Meadows J. W., Armani R. J., Callis E. L. and Essling A. M. (1980) Half-life of ${ }^{230}$ Th. Phys. Rev. C 22, 750-754.

Milankovitch M. M. (1941) Canon of insolation and the ice-age Problem (Königlich Serbische Akademie, Belgrade, Yugoslavia, 1941). J. Imbrie, K. P. Imbrie, Ice Ages: Solving the Mystery (Enslow, Short Hills, NJ, 1979).

Montaggioni L. F. (2005) History of Indo-Pacific coral reef systems since the last glaciation: development patterns and controlling factors. Earth Sci. Rev. 71(1-2), 1-75.

Pandolfi J. M. (1995) Geomorphology of the uplifted pleistocene atoll at Henderson Island, Pitcairn Group. Biol. J. Linn. Soc. 56(1-2), 63-77.

Parrenin F., Barnola J. M., Beer J., Blunier T., Castellano E., Chappellaz J., Dreyfus G., Fischer H., Fujita S., Jouzel J., Kawamura K., Lemieux-Dudon B., Loulergue L., MassonDelmotte V., Narcisi B., Petit J. R., Raisbeck G., Raynaud D., Ruth U., Schwander J., Severi M., Spahni R., Steffensen J. P., Svensson A., Udisti R., Waelbroeck C. and Wolff E. (2007) The EDC3 chronology for the EPICA dome $\mathrm{C}$ ice core. Climate Past 3(3), 485-497.

Paulay G. (1989) Marine invertebrates of the Pitcairn Islands: species composition and biogeography of corals, molluscs, and echinoderms. Atoll Res. Bull. 326, 1-28.

Potter E. K., Esat T. A., Schellmann G., Radtke U., Lambeck K. and McCulloch M. T. (2004) Suborbital-period sea-level oscillations during marine isotope substages $5 \mathrm{a}$ and $5 \mathrm{c}$. Earth Planet. Sci. Lett. 225(1-2), 191-204.

Potter E. K., Stirling C. H., Andersen M. B. and Halliday A. N. (2005a) High precision Faraday collector MC-ICPMS thorium isotope ratio determination. Int. J. Mass Spectrom. 247(1-3), $10-17$.

Potter E. K., Stirling C. H., Wiechert U. H., Halliday A. N. and Spotl C. (2005b) Uranium-series dating of corals in situ using laserablation MC-ICPMS. Int. J. Mass Spectrom. 240(1), 27-35.

Richards D. A. and Dorale J. A. (2003) Uranium-series chronology and environmental applications of speleothems. In UraniumSeries Geochemistry, vol. 52, pp. 407-460.

Robinson L. F., Adkins J. F., Fernandez D. P., Burnett D. S., Wang S. L., Gagnon A. C. and Krakauer N. (2006) Primary U distribution in scleractinian corals and its implications for $\mathrm{U}$ series dating. Geochem. Geophys. Geosyst. 7, Q05022.
Robinson L. F., Henderson G. M., Hall L. and Matthews I. (2004) Climatic control of riverine and Seawater uranium-isotope ratios. Science 305(5685), 851-854.

Robinson L. F., Henderson G. M. and Slowey N. C. (2002) U-Th dating of marine isotope stage 7 in Bahamas slope sediments. Earth Planet. Sci. Lett. 196(3-4), 175-187.

Rohling E. J., Grant K., Bolshaw M., Roberts A. P., Siddall M., Hemleben C. and Kucera M. (2009) Antarctic temperature and global sea level closely coupled over the past five glacial cycles. Nat. Geosci. 2(7), 500-504.

Scholz D. and Mangini A. (2006) Estimating the uncertainty of coral isochron U-Th ages. Quat. Geochronol. 1(4), 279-288.

Scholz D. and Mangini A. (2007) How precise are U-series coral ages? Geochim. Cosmochim. Acta 71(8), 1935-1948.

Scholz D., Mangini A. and Felis T. (2004) U-series dating of diagenetically altered fossil reef corals. Earth Planet. Sci. Lett. 218(1-2), 163-178.

Scholz D., Mangini A. and Meischner D. (2006) U-redistribution in fossil coral reef corals from Barbados, West Indies, and sea level reconstruction for MIS 6.5. In The Climate of Past Interglacials (eds. F. Sirocko, M. Claussen, T. Litt and M. F. Sanchez-Goni). Elsevier, Amsterdam Heidelberg, New York, pp. 119-140.

Siddall M., Rohling E. J., Almogi-Labin A., Hemleben C., Meischner D., Schmelzer I. and Smeed D. A. (2003) Sea-level fluctuations during the last glacial cycle. Nature 423(6942), 853858.

Stirling C. H. and Andersen M. B. (2009) Uranium-series dating of fossil coral reefs: extending the sea-level record beyond the last glacial cycle. Earth Planet. Sci. Lett. 284(3-4), 269-283.

Stirling C. H., Andersen M. B., Potter E.-K. and Halliday A. N. (2007) Low temperature isotope fractionation of uranium. Earth Planet. Sci. Lett. 264, 208-225.

Stirling C. H., Esat T. M., Lambeck K. and McCulloch M. T. (1998) Timing and duration of the Last Interglacial: evidence for a restricted interval of widespread coral reef growth. Earth Planet. Sci. Lett. 160(3-4), 745-762.

Stirling C. H., Esat T. M., Lambeck K., McCulloch M. T., Blake S. G., Lee D. C. and Halliday A. N. (2001) Orbital forcing of the marine isotope stage 9 interglacial. Science 291(5502), 290-293.

Stirling C. H., Esat T. M., McCulloch M. T. and Lambeck K. (1995) High-precision U-series dating of corals from westernAustralia and implications for the timing and duration of the last interglacial. Earth Planet. Sci. Lett. 135(1-4), 115-130.

Stirling C. H., Halliday A. N., Potter E.-K., Andersen M. B. and Zanda B. (2006) A low initial abundance of ${ }^{247} \mathrm{Cm}$ in the early solar system: implications for r-process nucleo-synthesis. Earth Planet. Sci. Lett. 251(3-4), 386-397.

Thomas A. L., Henderson G. M., Deschamps P., Yokoyama Y., Mason A. J., Bard E., Hamelin B., Durand N. and Camoin G. (2009) Penultimate deglacial sea-level timing from U/Th dating of Tahitian Corals. Science 324(5931), 1186-1189.

Thompson W. G. and Goldstein S. L. (2005) Open-system coral ages reveal persistent suborbital sea-level cycles. Science 308(5720), 401-404.

Thompson W. G., Spiegelman M. W., Goldstein S. L. and Speed R. C. (2003) An open-system model for U-series age determinations of fossil corals. Earth Planet. Sci. Lett. 210(1-2), 365-381.

Villemant B. and Feuillet N. (2003) Dating open systems by the 238U-234U-230Th method: application to Quaternary reef terraces. Earth Planet. Sci. Lett. 210(1-2), 105-118.

Yokoyama Y., Esat T. M. and Lambeck K. (2001) Last glacial sealevel change deduced from uplifted coral terraces of Huon Peninsula, Papua New Guinea. Quatern. Int. 83-5, 275-283. 